San Jose State University

SJSU ScholarWorks

Master's Theses

Master's Theses and Graduate Research

Summer 2016

\title{
Trapped in endoderm-1 Reveals a Novel Role for Fruitless in Drosophila melanogaster Courtship
}

Peter Luu

San Jose State University

Follow this and additional works at: https://scholarworks.sjsu.edu/etd_theses

\section{Recommended Citation}

Luu, Peter, "Trapped in endoderm-1 Reveals a Novel Role for Fruitless in Drosophila melanogaster Courtship" (2016). Master's Theses. 4726.

DOI: https://doi.org/10.31979/etd.68k8-vxjn

https://scholarworks.sjsu.edu/etd_theses/4726

This Thesis is brought to you for free and open access by the Master's Theses and Graduate Research at SJSU ScholarWorks. It has been accepted for inclusion in Master's Theses by an authorized administrator of SJSU ScholarWorks. For more information, please contact scholarworks@sjsu.edu. 


\author{
A Thesis \\ Presented to \\ The Faculty of Department of Biological Sciences \\ San José State University
}

\author{
In Partial Fulfillment \\ of the Requirement for the Degree \\ Master of Science
}

by

Peter Luu

August 2016 
(C) 2016

Peter Luu

ALL RIGHTS RESERVED 
The Designated Thesis Committee Approves the Thesis Titled:

TRAPPED IN ENDODERM 1 REVEALS A NOVEL ROLE FOR FRUITLESS IN DROSOPHILA MELANOGASTER COURTSHIP

by

Peter Luu

APPROVED FOR THE DEPARTMENT OF BIOLOGICAL SCIENCES SAN JOSÉ STATE UNIVERSITY

August 2016

Dr. Rachael French

Dr. David Tran

Dr. Katie Wilkinson
Department of Biological Science

Department of Biological Science

Department of Biological Science 


\section{ABSTRACT \\ TRAPPED IN ENDODERM 1 REVEALS A NOVEL ROLE FOR FRUITLESS IN DROSOPHILA MELANOGASTER COURTSHIP}

\section{By Peter Luu}

Understanding how genes can direct behaviors has been a prevailing goal of neuroscience. Courtship in D. melanogaster is a complex yet stereotyped array of behaviors established by sex-specific genetic pathways mediated by sensory inputs by the nervous system. However, much remains to be discovered about the neurobiological and molecular mechanisms that regulate this complex set of behaviors. We have identified a group of cells expressing Trapped in endoderm 1 (Tre1) in which male Fruitless proteins are required to reduce the speed of courtship initiation. Trel encodes a G-proteincoupled receptor required for establishment of cell polarity and cell migration and has previously not been shown to be involved in courtship behavior. By monitoring the latency to courtship initiation of male flies, we found the expression of female-specific transcription factors in Tre1-expressing neurons, or "feminization," resulted in rapid courtship initiation. The Trel-feminized males produced an increased number of offspring when challenged in a competitive fertility assay, suggesting that rapid courtship initiation led to a reproductive advantage. Interestingly, this did not hinder male flies' ability to select an appropriate mate when they were confronted with a variety of mating targets. Using immunofluorescence, we showed that Trel is expressed in a sexually dimorphic pattern in the central and peripheral nervous systems. Ultimately, we believe these cells may participate in an unforeseen "quality control" step that ensures the correct performance of the courtship ritual. 


\section{ACKNOWLEDGEMENTS}

I would like to thank my family for their support throughout my college career.

The researchers, faculty, and staff of the biology department for taking the time from their work to create a helpful environment.

Members of the French Lab for giving both a learning and mentoring experience (and putting up with me). With a special thanks to Payam Khodabakshi who helped with technical issues and has always been around to help at any moment.

Sadaf Zaki for helping me through the bulk of my research and filling in at odd hours. Without her, our publication would have been impossible.

I am especially indebted to Dr. Rachael French for culminating my academic and scientific abilities during the six years of my studies at San José State University. Thank you so much. 


\section{TABLE OF CONTENTS}

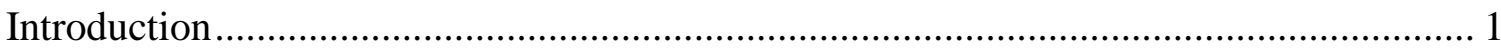

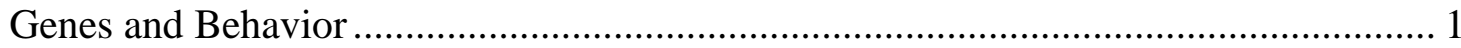

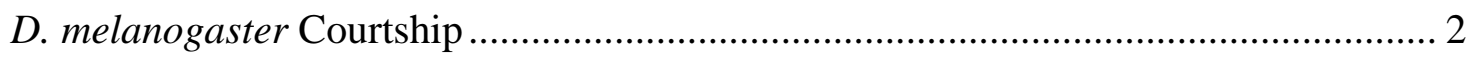

D. melanogaster Nervous System and Courtship ................................................... 3

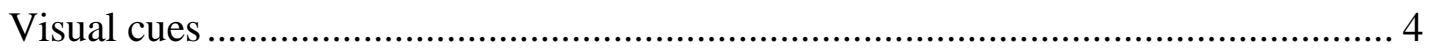

Pheromonal and other chemosensory cues .................................................... 5

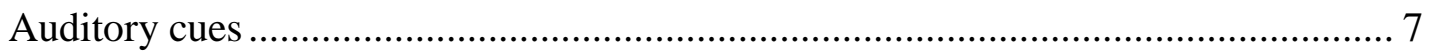

Fruitless and Behavioral Sex Determination ....................................................... 8

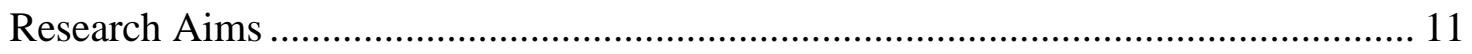

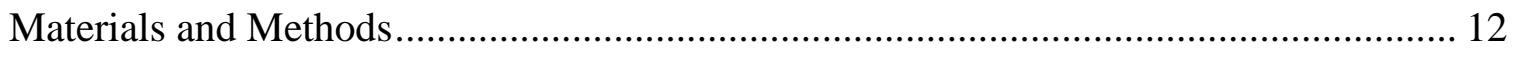

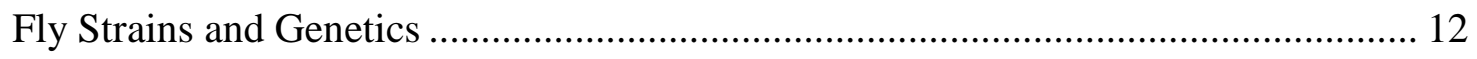

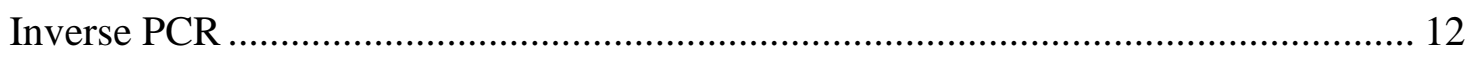

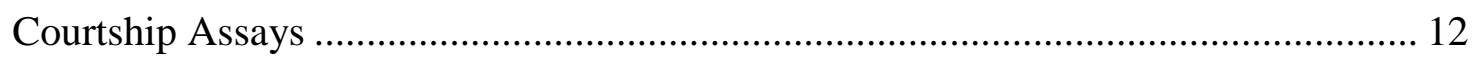

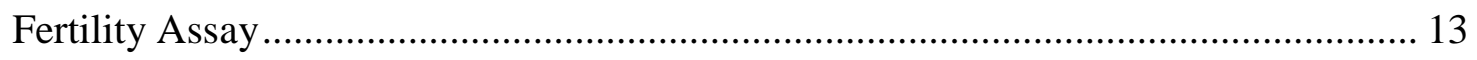

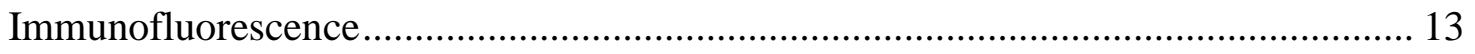

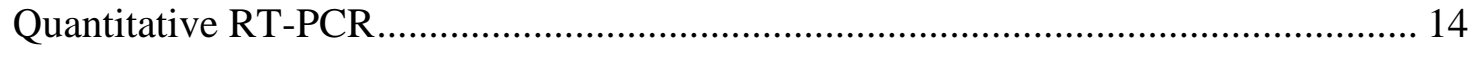

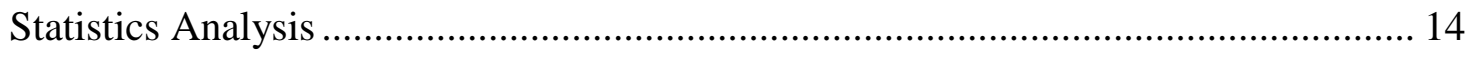

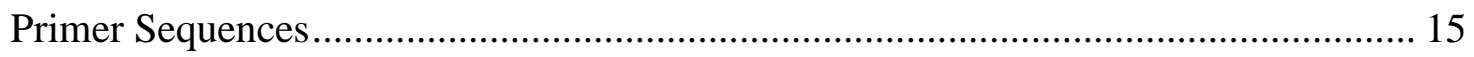


Results 16

Tissue-Specific Feminization Using the GAL4 Line 9-210 ..................................... 16

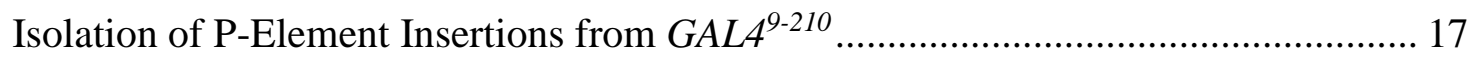

Feminization of Tre-1-Expressing Cells Causes Rapid Courtship Initiation ............... 18

Tre1-GAL4 is Expressed in a Sexually Dimorphic Pattern in Both the Central and Peripheral Nervous Systems ............................................................................ 20

Tre1-GALA/Y; UAS-TraF Males Have Increased Reproductive Fitness ..................... 23

Tre1-GAL4 Neurons Are Not Required to Distinguish Mated from Unmated Females 28

Tre1-GAL4 Neurons Are Not Required to Distinguish Male Flies from Female Flies 29

Tre1-GAL4 Neurons Are Not Required for Identification of Conspecific Females ..... 30

Tre1-GAL4 May Be a Partial Loss of Function Allele of Tre1 ................................ 31

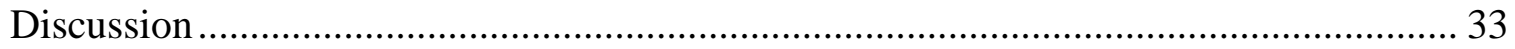

D. melanogaster Mating Behavior and the Role of the Tre 1-GAL4 Neurons ............. 34

The Tre1 Receptor and Courtship Behavior ..................................................... 35

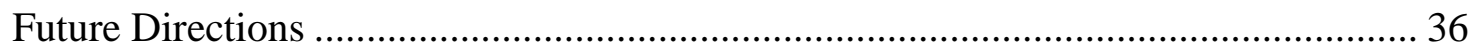

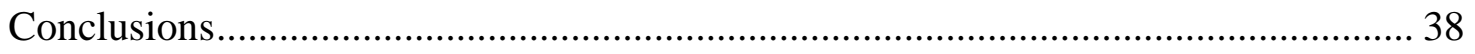

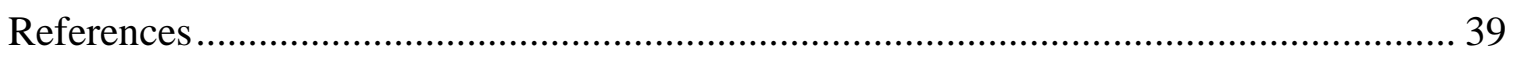




\section{LIST OF FIGURES}

1 The Courtship Ritual in D. melanogaster

2 Behavioral Sex Determination in D. melanogaster .......................................10

$3 \quad G A L 4^{9-210} / Y ; U A S-T r a^{F} /+$ Males Display Rapid Courtship Initiation ..................18

$4 \quad$ Representative DNA Gel of Isolation of Transposons ..................................19

5 Tre 1-GAL4/Y;UAS-Tra ${ }^{F} /+$ Males Display Rapid Initiation of Wing Song.........20

6 Sexually Dimorphic Tre 1-GAL4 Expression Pattern.......................................23

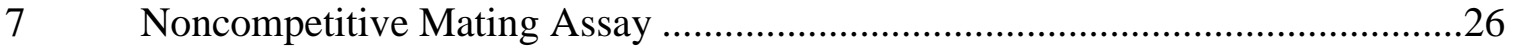

$8 \quad$ Expected Progeny of Tre 1-GALA/Y; UAS-TraF Males ...................................27

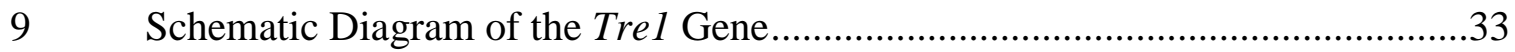

$10 \quad$ Expression of Tre1 1 RNA in Tre1-GAL4 Flies ................................................33 


\section{LIST OF TABLES}

1 The Effects of Common Courtship Pheromones...........................................

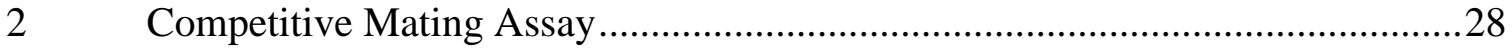

3 Courtship Latency of D. melanogaster Males with Mated Females....................30

4 Courtship Latency of D. melanogaster Males with Unmated Males ...................31

$5 \quad$ Courtship Latency of D. melanogaster Males with Females ….........................32 of Sibling Species 


\section{Introduction}

\section{Genes and Behavior}

Humans and other animals are born with a characteristic body plan and morphology, but we often overlook behavior as similarly heritable. Whether it is predator avoidance or a courtship pattern, certain behaviors have persisted through generations, suggesting a genetic component. This raises a long-standing question in behavioral neuroscience: do genes control behavior? How do genes direct neurodevelopment to integrate series of sensory inputs and motor outputs to orchestrate a complex behavior?

In a broad sense, behaviors can encompass anything from movement (courtship, nest building, and predation) to regulation (heart rate, breathing, and balance) (Lorenz, 1950). Instinctive or innate behaviors are stereotyped behaviors of an organism induced by specific sensory stimuli, also called a fixed action pattern. Innate behaviors are capable of being performed without training. The study of these behaviors offers the advantage of dedicated neurological pathways that are more amenable to genetic analyses.

Understanding how genes organize neuronal circuitry will help elucidate how the nervous system generates complex behaviors. However, delineating the mechanism by which genes control a behavior is challenging. For any innate behavior, there is a myriad of genetic effects working to integrate environmental (sensory) cues with hard-wired neuronal circuitry. To understand how genes, the brain, and behavior are associated, we require a tractable gene expression system, a well-characterized nervous system, and a 
stereotyped set of responses. Male courtship behavior in D. melanogaster has emerged as an excellent model system for the study of genetic specification of behavior.

\section{D. melanogaster Courtship}

D. melanogaster courtship involves a complex but stereotyped array of sexually dimorphic behaviors that have been studied for over 50 years (Shorey, 1962) (Figure 1). The male first recognizes olfactory and visual cues from the female and orients himself towards her. Next, he pursues her and taps the female to sample non-volatile chemicals present on her cuticle. He then extends and vibrates one wing towards the female to play a species-specific courtship song. If she is responsive, she stops movement, allowing the male to lick her genitalia to open the vaginal plates. The male then mounts the female and curls his abdomen to attempt copulation. A receptive female copulates with the male, allowing for the transfer of semen, which results in both fertilization and a reduction in female sexual receptivity (Tram \& Wolfner, 1998). All of these steps are performed correctly and in the correct order by naive males (Hall, 1994), making $D$. melanogaster courtship an ideal model for the study of the genetic programming of complex innate behaviors. 


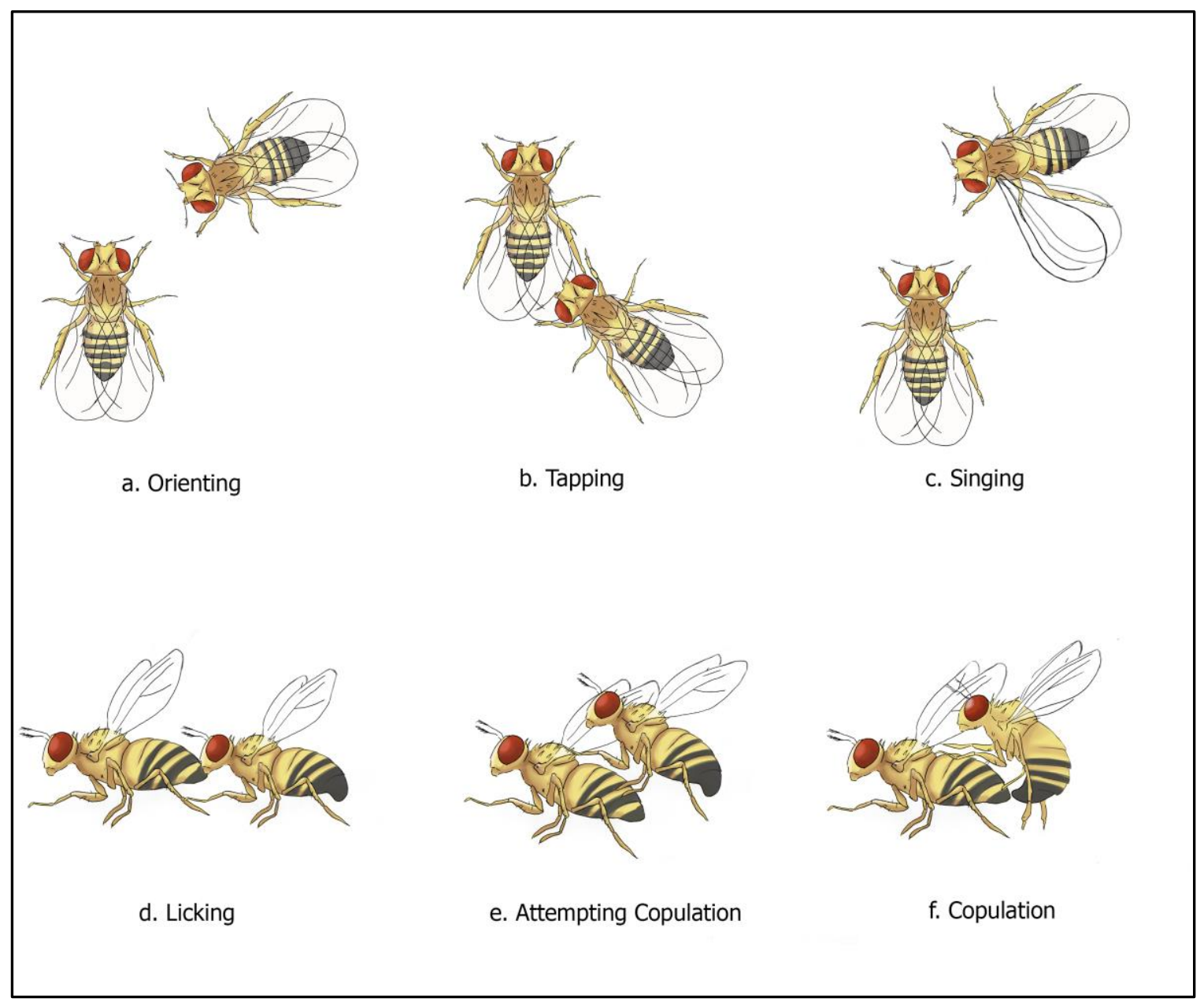

Figure 1. The courtship ritual in D. melanogaster. (a) The male first orients towards and follows the female, (b) then taps her with his forelegs, (c) extends one wing towards the female, and vibrates it to generate a species-specific courtship song. (d) He then licks her genitalia and (e) curls his abdomen to attempt copulation. If the female is receptive (has not recently mated), (f) copulation will follow.

\section{D. melanogaster Nervous System and Courtship}

Courtship initiation in D. melanogaster males relies on sensory information including visual, auditory, mechanosensory, and chemical cues which remains consistent within species (Boake, 1997; Greenspan \& Ferveur, 2000). Because the process happens in a sex-specific fashion, integrations of these cues must rely on a sexually dimorphic 
nervous system. The male isoform of Fruitless, $\mathrm{Fru}^{\mathrm{M}}$, generally mediates development of the nervous system by targeting neuronal morphogenetic genes (Neville et al., 2014). The expression of $f r u^{M}$ in females is sufficient to generate male courtship behavior, whereas the loss $f r u^{M}$ in males causes the absence of courtship behaviors (Demir \& Dickson, 2005). Thus, to understand how genes control behavior, it is crucial to identify the differences between the male and female nervous systems.

The D. melanogaster nervous system has a volume of $\sim 0.07 \mathrm{~mm}^{3}$ (Rein et al., 2002). Of roughly 135,000 neurons in the supraesophageal ganglion, about 2,000 express $f r u^{M}$ and are found in the olfactory, gustatory, auditory, and mechanosensory systems (Alivisatos et al., 2012; Datta et al., 2008). This suggests an integration of sensory information during courtship that is mediated by sex determination factors.

Visual cues. The optic lobes are located in the anterior and lateral position of the supraesophageal ganglion and process visual information (Yu et al., 2010). Despite the eye being dispensable for successful copulation (Mcrobert \& Tompkins, 1987), $f r u^{M}$ expression in the optic lobe likely mediates male-specific visual cues. About 30 neurons in the male optic lobe express fru, compared with about five neurons in the female optic lobe (Kimura et al., 2005). Several neurons from the optic lobe integrate with the lateral horn, a known region with high levels of fru expression (Ruta et al., 2010). Knockout of $f r u^{M}$ in the optic lobe affects locomotive behavior, such as rates of following and turning, during courtship (Lee et al., 2000). During the early stages of the courtship ritual, the male follows the female, wherein his ability to see the female correlates with the amount of visibility (Sakai et al., 1997). 
However, in the absence of light, the male D. melanogaster still performs the orientation and following stages of the courtship ritual, indicating that visual cues are less important than other forms of sensory input. Blind flies, as well as flies in dark environments, display delayed courtship initiation compared to seeing flies; this indicates that visual cues are important but not required for normal courtship initiation. Additionally, vision is not necessary for successful copulation in female flies (Markow, 1987).

Pheromonal and other chemosensory cues. A common feature among animals is the use of chemical cues, including pheromones, to modulate behavior. The two known brain regions that process pheromonal cues are the mushroom body and the lateral horn (Marin et al, 2002; Keene \& Waddell, 2007). The effects of a few pheromones in D. melanogaster are listed in Table 1. In D. melanogaster, pheromones are synthesized by specialized cells called oenocytes (Makki et al., 2014). There are two general categories of pheromones: volatile and non-volatile.

Volatile pheromones, as their name implies, do not require physical contact for their effects; instead, they disperse to olfactory receptor neurons (ORNs) in the antenna and maxillary palp. The ORNs are housed in chemosensory hair-like structures called sensilla and project to the antennal lobe and subsequently to the mushroom body and the lateral horn. One example of such a cue is the volatile pheromone 11-cis-vaccenyl acetate $(\mathrm{cVA})$. cVA is expressed by male fruit flies and influences courtship behavior of both male and female flies over the range of a few centimeters (Antony \& Jallon, 1982; Kurtovic et al., 2007). cVA activates the Or67d olfactory receptor present in antennal 
neurons in both sexes; however, it displays sexually dimorphic effects. Knockout of the Or67d receptor in males leads to indiscriminate courting of either sex, indicating a required function in mate selection in males (Kurtovic et al., 2007). On the other hand, when the Or67d receptor is knocked out in females, they become less receptive to male sexual advances (Kurtovic et al., 2007). Finally, high levels of cVA in conditions where there is a high density of males lead to aggressive behaviors (Liu et al., 2011). Based on the studies of Kurtovic et al. (2007) and Liu et al. (2011), it is clear that cVA functions to inhibit mating behavior in male while promoting mating in females.

Nonvolatile pheromones are exchanged through physical contact and act through gustatory receptors on the forelegs and proboscis during the licking and tapping steps of courtship. The male foreleg expresses specific gustatory receptors to detect inhibitory pheromones, such as the hydrocarbon 7-tricosene (7-T) (Ferveur \& Sureau, 1996; Savarit et al., 1999). Similar to cVA, 7-T helps to inhibit male-male courtship while inducing aggressive behavior (Wang et al., 2011). Likewise, when males are perfumed with 7-T, females mate faster and more frequently (Grillet, Dartevelle, \& Ferveur, 2006). Thus, like cVA, 7-T inhibits male-male mating behavior while promoting female receptivity. 
Table 1. The Effects of Common Courtship Pheromones

\begin{tabular}{|c|c|c|}
\hline Chemical Name & Abbr. & Effect on Courtship \\
\hline 5-tricosene or 5-C23:1 & $(5-\mathrm{T})$ & $\dashv$ Tapping \\
\hline 7-tricosene or 7-C23:1 & $(7-\mathrm{T})$ & $\begin{array}{l}\dashv \text { Wing song, attempted copulation, licking } \\
\rightarrow \text { Female receptivity }\end{array}$ \\
\hline 7-pentacosene or 7-C25:1 & $(7-\mathrm{P})$ & $\rightarrow$ Male-male courtship \\
\hline 9-pentacosene or 9-C25:1 & $(9-\mathrm{P})$ & $\rightarrow$ Attempted copulation \\
\hline 7, 11 heptacosadiene & $(7,11 \mathrm{HD})$ & $\rightarrow$ Wing song, attempted copulation, licking \\
\hline 7, 11 heptacosene & $(7,11 \mathrm{ND})$ & $\rightarrow$ Wing song, attempted copulation, licking \\
\hline 11-cis-vaccenyl acetate & $(\mathrm{cVA})$ & $\rightarrow$ Copulation \\
\hline
\end{tabular}

Notes. Adapted from Cobb \& Jallon, 1990; Ferveur \& Sureau, 1996; Liu et al., 2011. $\dashv$ is inhibitory, $\rightarrow$ is stimulatory.

Auditory cues. During courtship, D. melanogaster males activate indirect flight muscles to vibrate their wings and produce an acoustic cue (Shirangi et al., 2013). This wing song consists of two phases, a "sine" phase and a "pulse" phase. The sine phase is species non-specific and thought to increase female receptivity, whereas the pulse phase is species-specific (Ewing \& Bennet-Clark, 1968). The auditory circuit begins at the second segment of the antenna which houses auditory sensory neurons (Lai et al., 2012). These neurons project to antennal mechanosensory and motor centers (AMMC) in the brain (Lai et al., 2012).

The female hears the vibration and then becomes more receptive to copulation. Consequently, females with a deficit in hearing are less likely to copulate (Markow, 1987). For the male initiator of courtship, however, auditory deficiency does not affect copulation (Markow, 1987). 


\section{Fruitless and Behavioral Sex Determination}

The fruitless (fru) gene is the master regulator of male courtship behavior. fru is both necessary and sufficient for every step of courtship and is required independently at each step (Demir \& Dickson, 2005). The fru gene spans $120 \mathrm{~kb}$ of genomic DNA, contains four different promoters (fruPl-fruP4) and encodes 12 known isoforms of a bric-a-brac/tramtrack/Broad (BTB)/zinc finger transcription factor. fruPl is expressed in a sex-specific fashion, whereas $f r u P 2, P 3$, and $P 4$ are expressed in both sexes and result in transcription of proteins that are essential for survival (Ryner et al., 1996).

Transcripts initiated from the fru $\mathrm{P} 1$ promoter are sex-specifically spliced under the control of the sex-determining pathway via the splicing factors Tra and Tra-2 (Figure 2). Male-specific splicing of $f r u \mathrm{P} 1$ transcripts results in full-length $\mathrm{Fru}^{\mathrm{M}}$ proteins, while female-specific splicing results in truncated Fru proteins due to the introduction of a premature stop codon (Anand et al., 2001). There are three protein isoforms of $\mathrm{Fru}^{\mathrm{M}}$ (FruA, FruB, and FruC) that control neuronal arborization and courtship behavior (von Philipsborn et al., 2014).

$f r u^{M}$ mutant male behavior varies from courting male and female flies indiscriminately, to skipping steps, to complete lack of courtship behavior (Hall, 1994). Consistent with its role as a master regulator of courtship behavior, when $f r u^{M}$ expression is driven in female flies, they exhibit male courtship behaviors towards other females (Demir \& Dickson, 2005; Manoli et al., 2005). When $f r u^{M}$ expression is knocked down in neurons in males, which "feminizes" the cells, the flies will appear morphologically male, but lack courtship behaviors that indicates a requirement for $\mathrm{Fru}^{\mathrm{M}}$ proteins in sex 
determination in the nervous system (Ryner et al., 1996). Finally, Fru ${ }^{\mathrm{M}}$ transcription factors are expressed in $~ 2 \%$ of neurons in the male brain and ventral nerve cord (VNC) (Alivisatos et al., 2012). 


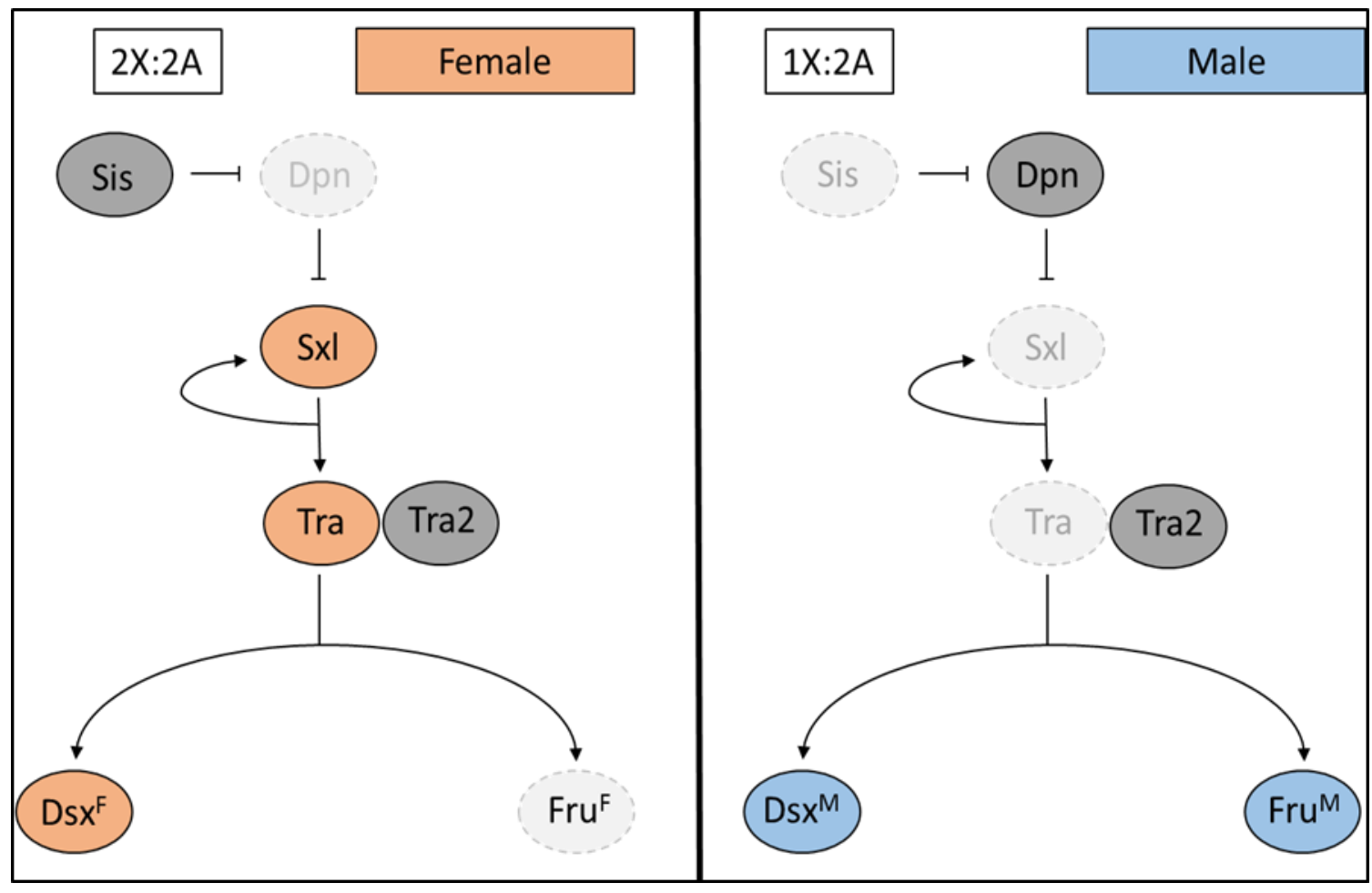

Figure 2. Behavioral sex determination in D. melanogaster. Control of Fruitless splicing starts with the "measuring" of the autosome to X chromosome ratio, where a normal female has two X chromosomes to two sets of autosomes (2X:2A) and normal a male has one $\mathrm{X}$ chromosome to two sets of autosomes (1X:2A). A $2 \mathrm{X}: 2 \mathrm{~A}$ ratio results in increased expression of the $\mathrm{x}$-linked gene sisterless, which inhibits expression of the autosomal gene Deadpan, allowing the expression of sex-lethal $(\mathrm{sxl})$. sxl encodes a splicing factor, which drives female-specific splicing of transformer (tra). tra encodes yet another splicing factor (TraF) that directs female-specific splicing of $f r u$ transcripts. $f r u^{F}$ transcripts encode non-functional, truncated proteins. In males, the lack of TraF leads to male-specific splicing of fru P1 transcripts, resulting in full-length $\mathrm{Fru}^{\mathrm{M}}$ proteins. TraF also regulates the splicing of another sex specific protein, Doublesex (Dsx), to a female isoform, Dsx ${ }^{\mathrm{F}}$, which mediates the feminization of somatic tissues. 


\section{Research Aims}

Typically, disruption of $f r u^{M}$ expression leads to a delays in, or absence of, normal courtship behaviors. Here we have defined a set of neurons (Tre 1-GALA neurons) in which downregulation of $f r u^{M}$ causes unusually rapid initiation of courtship. Rapid courtship initiation would seem advantageous in nature by providing that leads to more offspring; however, there may be less apparent disadvantages. Males lacking $f r u^{M}$ expression in Tre1-GAL4 neurons may be skipping a checkpoint during mate selection, which might allow rapid courtship initiation, but reduced reproductive success in the wild. Alternatively, the fate of the Tre 1-GAL4 cells may be altered by the absence of FruM, resulting in a previously uncharacterized gain-of-function effect on courtship initiation. This thesis aims to:

- Confirm previous results by feminizing 9-210 cells by expressing $\operatorname{Tra}^{F}$

- Identify the GAL4 line that causes rapid courtship initiation in strain 9-210

- Further characterize the courtship and mating phenotypes of males with rapid courtship initiation

- Identify the neurons that are important for the 9-210 courtship phenotype 


\section{Materials and Methods}

\section{Fly Strains and Genetics}

The $P[G A W B]$ enhancer trap line $G A L 4^{9-210}$ was a kind gift from Ulrike Heberlein (Meissner et al., 2011). Isolation of the three X-linked P-elements was accomplished by crossing GAL4 $4^{9-210}$ females with $\mathrm{w}^{1118}$; Wild Type Berlin males. Heterozygous females were selected in which recombination was free to occur, allowing the isolation of 50 recombinant lines. Identification of the individual P-element insertions present in recombinant lines was accomplished using PCR. $w^{1118}$; Wild Type Berlin is our laboratory control strain. Tre $1^{E P 496}$ was obtained from the Bloomington Drosophila stock center (stock number: 10089). The $U A S-m C D 8-G F P$ and $U A S-T r a^{F}$ lines were a kind gift from Bruce Baker. D. simulans and D. mauritiana were a kind gift from Theresa Logan-Garbisch.

\section{Inverse PCR}

Identification of the P-element insertion sites was performed using inverse PCR, according to the Berkeley Drosophila Genome Project (BDGP) protocol. Genomic DNA was extracted using ethanol precipitation, digested with MspI (New England Biolabs), ligated at low DNA concentration to favor circularization, then subjected to PCR with primers GawB5' out and GawB5'in. Resulting PCR products were cloned into the pCR4TOPO-TA vector (Life Technologies) and sequenced with M13 for M13R primers.

\section{Courtship Assays}

Courtship assays were performed according to published protocols (Villella et al. 1997). Virgin males were kept in isolation for 2-3 days after eclosion. Each male was 
then presented with a single 1-2 day-old $w^{1118} ;$ WTB virgin female. Single male and female pairs were placed into custom plexiglass chambers $10 \mathrm{~mm}$ in diameter and $6 \mathrm{~mm}$ in height, separated by plastic transparencies. Contact between pairs was initiated by removal of the transparencies. Courtship behavior was recorded using Leica MZ8 in only infrared light for $20 \mathrm{~min}$.

\section{Fertility Assay}

For the noncompetitive fertility assay, a single 2-3 day-old male fly was paired with a single 2-3 day-old virgin female fly. The flies were allowed to mate and lay eggs for 2 days, after which the adults were cleared from the vials. All flies eclosing from each vial were counted and averaged over all vials to calculate fertility of individual males. For the competitive fertility assay, two experimental males and two $w^{1118} ;$ WTB males were placed in a vial with five $w^{1118} ; W T B$ virgin females. All flies were $2-4$ days old. The adults were allowed to mate and lay eggs for 2 days, after which the adults were cleared from the vials. The resulting progeny were counted and scored for their eye color phenotype.

\section{Immunofluorescence}

The CNS and peripheral tissue were prepared from three to six-day-old flies raised under standard conditions according to Wu \& Luo (2006) with the following modifications: tissues were fixed for $1 \mathrm{~h}$, incubated with NGS block for $24 \mathrm{~h}$, stained in primary antibody for four days, and secondary for two days. NC82 mouse anti-Bruch pilot was used at 1:50 (Developmental Studies Hybridoma Bank AB 2314866). Rabbit anti-GFP was used at 1:750 (Life Technologies ref. number: A6455). Alexafluor 488 
Goat anti-Rabbit was used at 1:1000 (Jackson Immunoresearch ref: 111-545-144).

Alexafluor 594 Goat anti-Mouse was used at 1:1000 and provided by David Tran (Tran et al., 2014). Imaging was performed on LSM 700 using Zen blue imaging software and ImageJ with Fiji for post imaging analysis.

\section{Quantitative RT-PCR}

For quantitative reverse-transcriptase-mediated PCR (qRT-PCR), embryos, third instar larvae, pupae, and adult flies were snap-frozen on dry ice. Total RNA was extracted using Trizol reagent (Life Technologies, Carlsbad, CA) according to the manufacturer's instructions, resuspended in RNase-free water and stored at $-80^{\circ} \mathrm{C}$ until use. Total RNA $(2 \mu \mathrm{g})$ was reverse-transcribed using the High-Capacity RNA-to-cDNA Kit (Applied Biosystems, Carlsbad, CA) according to the manufacturer's instructions. cDNA was analyzed by quantitative real-time PCR using the Applied Biosystems 7300 Real-Time PCR System (Applied Biosystems). Ribosomal protein 49 (rp49) transcript levels were used as an endogenous normalization control for RNA samples, and relative mRNA abundance was calculated using the comparative $\Delta \Delta \mathrm{Ct}$ method (Schmittgen \& Livak, 2008). Each sample was analyzed in triplicate. As a negative control, we used DNase-treated nonreverse-transcribed mRNA samples; no significant amplification was observed in these samples.

\section{Statistics Analysis}

For courtship assays, one-way ANOVA was conducted with a Tukey's HSD posthoc analysis to determine significant differences in courtship log-transformed latency means (if $\mathrm{p}<0.05$ ). For graphs, latency was back-transformed. 
For competitive and non-competitive fertility assays, $\chi^{2}$ was used to determine significant differences (if $\mathrm{p}<0.05$ ). RStudio and Microsoft Excel 2013 were used for all statistical analyses.

\section{Primer Sequences}

Tre-1: $\quad$ left primer: 5'-TCGTTTCGTACTCGTGCATC-3'

right primer: 5'-TGGAAGTTATCGTGGTTGCG-3'

CG42343: 5'-GTACTCCCT GTCCCACTCCA-3';

GawB5'in: 5'-CAATAATGGGTTCTTTGGC GACGG-3'

GawB5'out: 5'-GCCGCACGTAAGGGTTAATG-3'

M13F: 5'-GTAAAACGACGGCCAG-3'

M13R: 5'-CAGGAAACA GCTATGAC-3'

Rp49: $\quad$ left primer: 5'-ACGTTGTGCAC CAGGAACTT-3'

right primer: 5'-CCAGTCGGATCGAT ATGCTAA-3' 


\section{Results}

\section{Tissue-Specific Feminization Using the GAL4 Line 9-210}

As described above, knocking down $\mathrm{Fru}^{\mathrm{M}}$ in the $P[G a w B] 9-210\left(G A L 4^{9-210}\right)$ cells by driving two copies of a $f r u^{M}-R N A i$ construct, $G A L 4^{9-210} / Y ; U A S-f r u^{M} I R /+; U A S$ $\mathrm{fru}^{M} I R /+$, in males led to a reduction in latency to courtship initiation. Courtship latency is defined here as the time elapsed between the first introduction of a female to the first unilateral wing extension (indicative of wing song) by the male. Courtship latency in $G A L 4^{9-210} / Y ; U A S-f r u^{M} I R /+; U A S-f r u^{M} I R /+$ males averaged $18 \mathrm{~s}$, compared with $28-32 \mathrm{~s}$ in heterozygous genetic background controls (Tran et al., 2014).

We confirmed the results of our previous study (Tran et al., 2014) by driving the expression of the female-specific isoform of the splice factor Transformer $\left(\operatorname{Tra}^{\mathrm{F}}\right)$, with $G A L^{9-210}$. As described in Figure 3, $\operatorname{Tra}^{\mathrm{F}}$ directs the female-specific splicing of fru transcripts, which, in females, results in the absence of full-length $\mathrm{Fru}^{\mathrm{M}}$ proteins. Thus expression of $\operatorname{Tra}^{F}$ in neurons that normally express $\mathrm{Fru}^{\mathrm{M}}$ proteins resulted in the feminization of those neurons (Heinrichs, et al., 1998). On average, GAL4 $4^{9-210}$; UAS$\operatorname{Tra}^{F}$ males initiated wing song within 19 s, while heterozygous controls averaged 29 and $37 \mathrm{~s}$ (Figure 3), similar to the effects seen with $U A S-f r u^{M} I R$. 


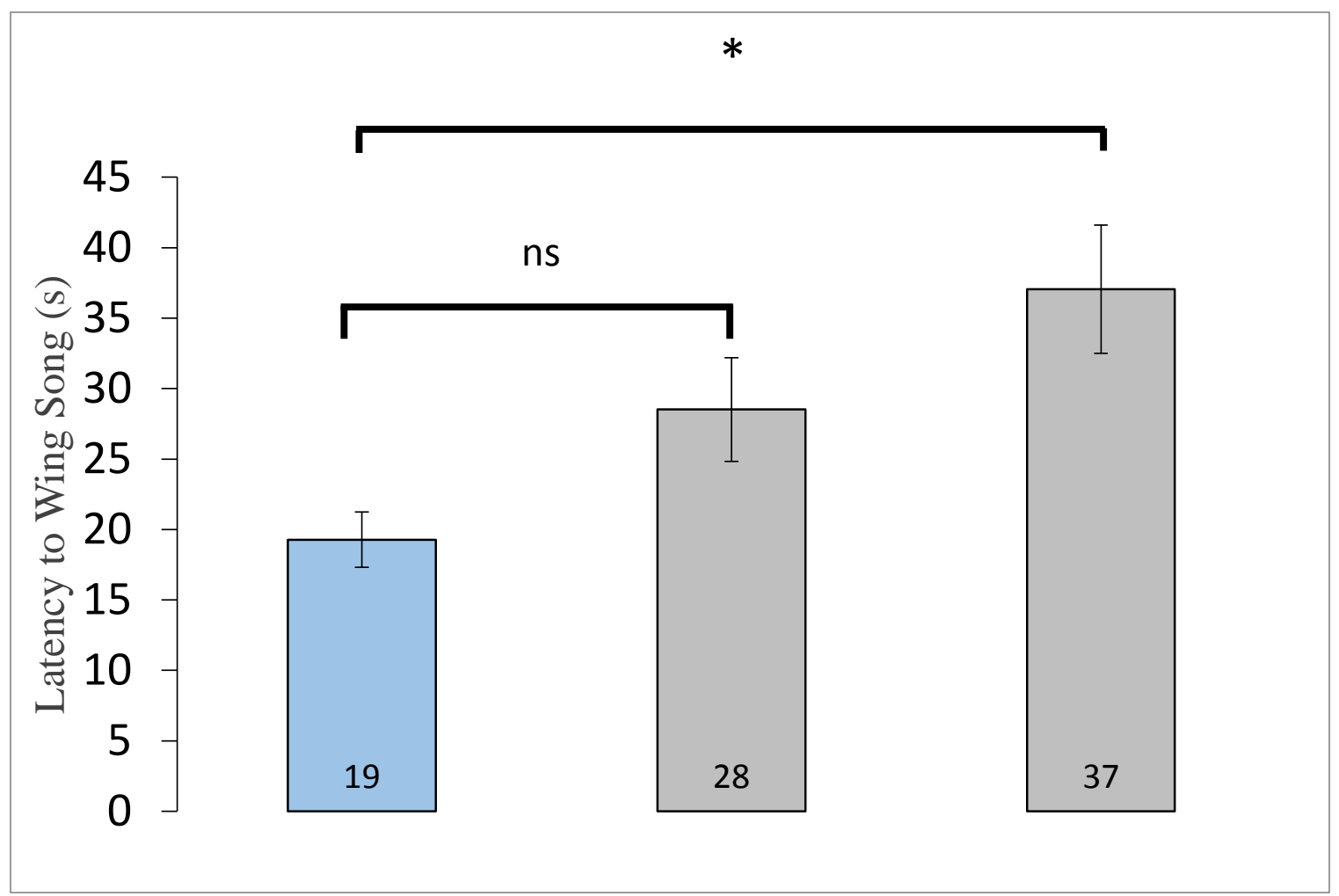

Figure 3. GAL4 $4^{9-210} / Y ; U A S-T r a^{F} /+$ males display rapid courtship initiation. GAL4-210 $/ Y$; UAS$\mathrm{Tra}^{F}$ males have a wing song latency of 19 seconds, while control animals initiate courtship in an average of 28 to 37 seconds. The blue bar represents the "feminized" group, whereas the grey bars represent heterozygous controls for each component of the GALA/UAS system. * denotes $\mathrm{P}$ $<0.05$, error bars indicate SD, mean latencies were log-transformed to obtain equal variance for the one-way ANOVA with Tukey's HSD post hoc analysis, mean latencies were backtransformed for graphs, $\mathrm{N}=22-24$ males.

\section{Isolation of P-Element Insertions from GAL4 ${ }^{9-210}$}

The $G A L 4^{9-210}$ line initially contained three independent X-linked P-element insertions at Trapped in endoderm 1 (Tre1), CG42343 and folded gastrulation (fog) (David Tran and Rachael French, unpublished data). Between the initial characterization of $G A L 4^{9-210}$ and our unpublished data, the transposon in fog was lost from the line, most likely due to it not being homozygous in the initial strain. The remaining two insertions were separated by meiotic recombination, generating 50 strains with a possible isolated 
P-element insertion. The identities of the isolated P-element insertions were confirmed using PCR with primers recognizing the P-element and the individual loci.

Representative examples of PCR results are shown in Figure 4. PCR of genomic DNA from strains PL1, PL3, and the positive control 9-210 yielded products using primers from both $C G 42343(C G)$ and Tre1, while strain PL2 amplified only with Tre1 primers, indicating that this strain contained a single P-element inserted in the Tre 1 locus.

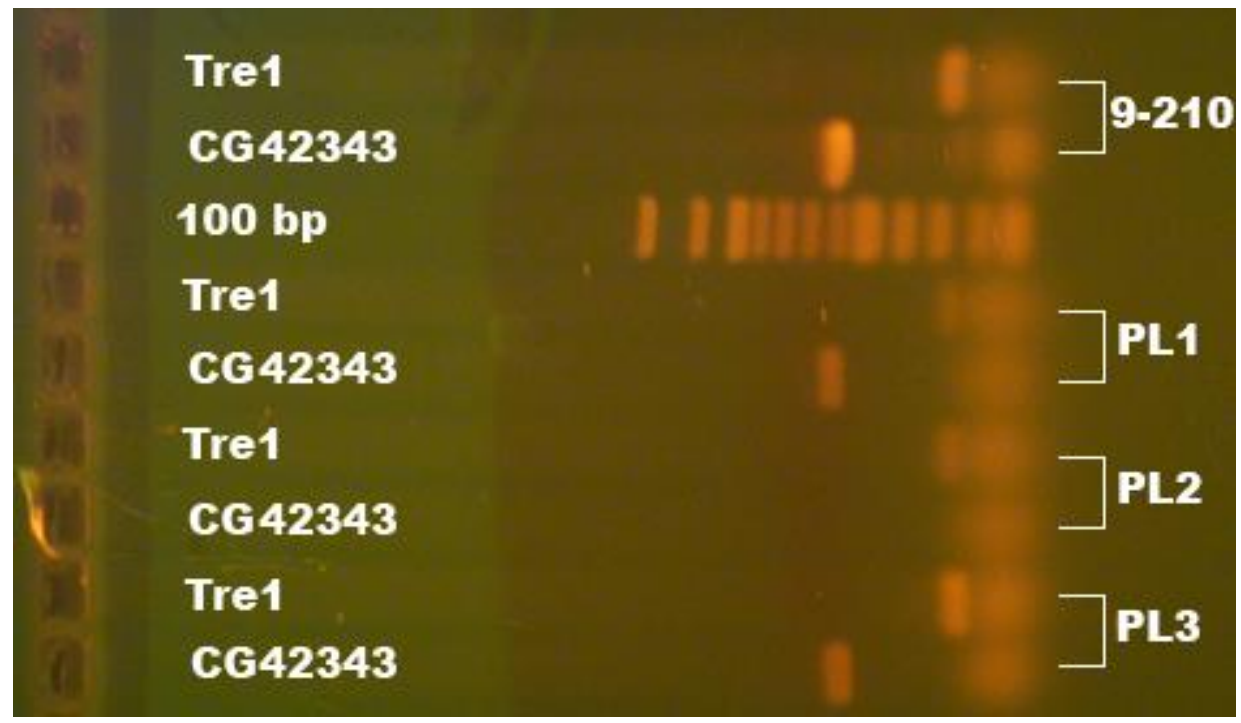

Figure 4. Representative DNA gel to confirm successful isolation of $P[G a w B]$ transposons. Tre 1 and CG42343 indicate the locus-specific primer used for that reaction. PL1-3 denotes the specific recombinant strain being assayed, 9-210 represents a positive control showing both Tre1 and CG bands. Amplicon sizes: Tre1 - 269 bp ; CG42343 - 507 bp.

\section{Feminization of Tre-1-Expressing Cells Causes Rapid Courtship Initiation}

We next tested the isolated Tre1-GAL4 and CG42343-GAL4 insertions for their ability to cause rapid courtship initiation when used to drive $U A S-T r a^{F}$. We found that Tre1-GAL4/Y;UAS-Tra ${ }^{F} /+$ males initiated wing song significantly faster than control males (Figure 5). Tre 1-GAL4/Y; UAS-Tra ${ }^{F} /+$ males have a courtship latency of $14 \mathrm{~s}$, 
while control animals initiated courtship on an average of 31 or $36 \mathrm{~s}$ (shown as grey columns). CG42343-GALA/Y; UAS-Tra ${ }^{\mathrm{F}} /+$ males averaged $53 \mathrm{~s}$, an increase that was not significant due to a high degree of variability in the sample. These results demonstrated that the elimination of $\mathrm{Fru}^{\mathrm{M}}$ proteins in Tre1-GAL4 expressing cells was responsible for the significantly reduced latency to court seen in $G A L 4^{9-210} / Y$; UAS-fru ${ }^{M} I R /+$ males.

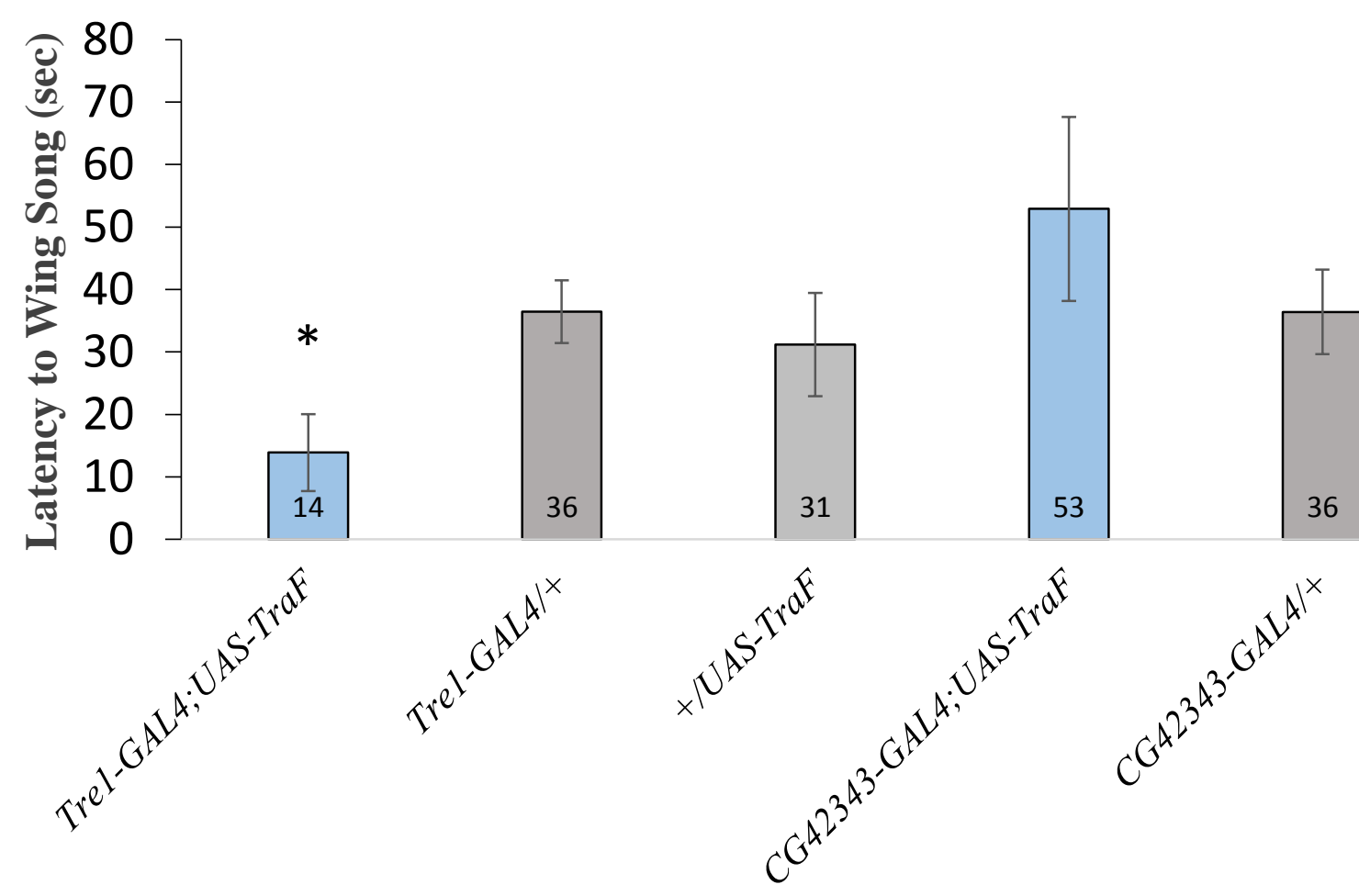

Figure 5. Tre1-GALA/Y; UAS-Tra ${ }^{F} /+$ males display rapid initiation of wing song. Tre 1-GAL4/Y; $U A S-\operatorname{Tra}^{F}$ males have a wing song latency lower than control animals. CG42343-GALA/UAS$\operatorname{Tra}^{F} /+$ males averaged higher than $C G 42343-G A L 4 / Y$ control animals. * denotes $\mathrm{P}<0.05$, differing from all other means. Error bars indicate SD, mean latencies were log-transformed to obtain equal variance for the one-way ANOVA with Tukey's HSD post hoc analysis, mean latencies were back-transformed for graphs, $\mathrm{N}=22-24$ males. 


\section{Tre 1-GAL4 is Expressed in a Sexually Dimorphic Pattern in Both the Central and Peripheral Nervous Systems}

In order to identify the cells that were being feminized in Tre 1-GAL4/Y;UAS-

$T r a^{F} /+$ males, we used Tre1-GAL4 to drive expression of $U A S-m C D 8$, a mouse

transmembrane glycoprotein fused to green fluorescent protein, under the control of the yeast UAS promoter. In the adult, Tre 1-GAL4 is expressed in a sexually dimorphic pattern in the olfactory sensory neurons (OSNs). In males, approximately 15 neurons in the $3^{\text {rd }}$ antennal segment (the primary D. melanogaster olfactory organ) express Tre1GAL4, while there is little to no expression in OSNs in females (Figure 6 A \& C). Consistent with this observation, Tre1-GAL4 is also expressed in two to three antennal lobe glomeruli (Figure 6 B \& D). Finally, there are extensive projections to the lateral horn ( $\mathrm{LH})$ of the brain in males and relatively few such projections seen in the female brain. This pattern is consistent with regions known to express $f r u^{M}$ (Alivisatos et al., 2012; Datta et al., 2008).

More importantly, the Tre1-GALA expression pattern is consistent with neurons that are involved in the detection and processing of olfactory cues. OSNs detect olfactory cues and project to specific glomeruli in the antennal lobe. Interneurons from the antennal lobe project to two major targets: neurons in the mushroom bodies of the brain (where neither $f r u^{M}$ nor Tre 1-GAL4 are expressed) and neurons in the LH. The LH is divided into the anterior and posterior sections where the anterior is involved in the processing of innate pheromonal signals (Gupta \& Stopfer, 2012; Jefferis et al., 2007). This suggests that the Tre1-GAL4 cells may be involved in the reception and/or 
processing of a chemosensory signal involved in mate selection. In addition to the sexually dimorphic expression described above, Tre 1-GAL4 is also expressed in the auditory neurons of the second antennal segment and their projection target, the antennal mechanosensory and motor center (AMMC) (Figure 2.4 A \& C) (Kamikouchietal. 2006). Finally, projections are found in the subesophageal ganglion (SOG) in both sexes (Figure 6 B \& D). 


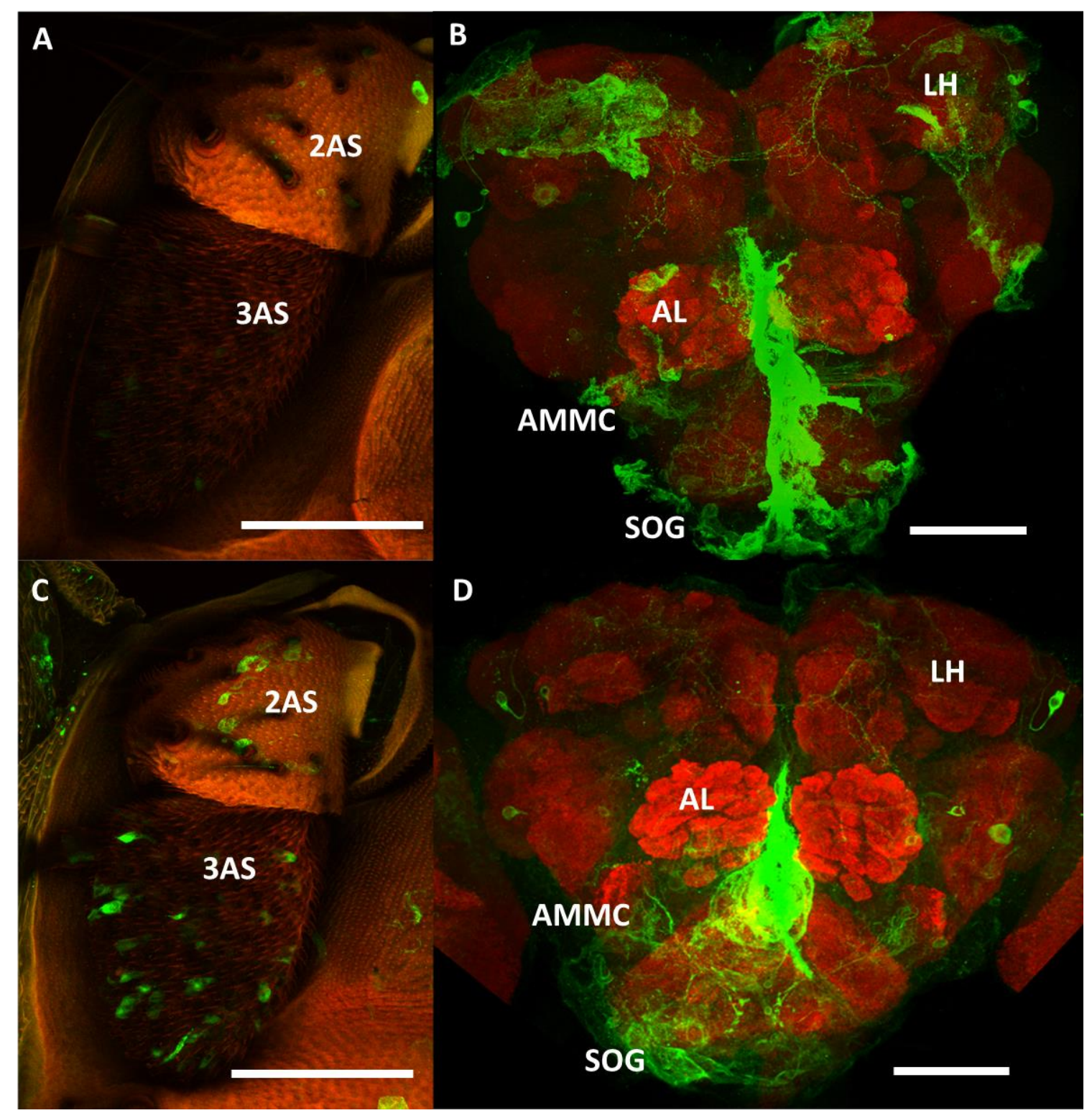

Figure 6. Sexually dimorphic Tre 1-GAL4 expression pattern in the male and female CNS. (A) Male $2^{\text {nd }}$ and $3^{\text {rd }}$ antennal segment. (B) Male CNS. (C) Female $2^{\text {nd }}$ and $3^{\text {rd }}$ antennal segment. (D) Female CNS. AS = antennal segment, $\mathrm{SOG}=$ subesophageal ganglion, $\mathrm{AMMC}=$ antennal mechanosensory and motor center, $\mathrm{AL}=$ antennal lobe, $\mathrm{LH}=$ lateral horn. Red channel shows background neuropil staining, green channel shows Tre1-GAL4 expression, scale bars represent $50 \mu \mathrm{m}$. 


\section{Tre1-GAL4/Y; UAS-TraF Males Have Increased Reproductive Fitness}

Given that feminizing the Tre 1-GAL4 neurons led to rapid courtship initiation, the phenomenon would seem to provide a potential mating advantage over wild type males. We tested the reproductive fitness or mating success of Tre1-GAL4/Y;UAS-TraF males in two ways. First, we tested their fertility in a noncompetitive assay with $w^{1118}$; WTB unmated females. Tre 1-GALA/Y; UAS-Tra ${ }^{F}$ males produce an average of 23 offspring per male, whereas the UAS-Tra ${ }^{\mathrm{F}} /+$ and $\operatorname{Tr} 1-G A L 4 / Y$ heterozygous background controls produced an average of 21 and 25 offspring, indicating that the fertility of Tre 1-GALA/Y; $U A S-\operatorname{Tra}^{F}$ males is normal (Figure 7).

We next tested Tre1-GALA/Y;UAS-Tra ${ }^{F} /+$ males in competitive mating assays to test the hypothesis that rapid courtship initiation results in a competitive mating disadvantage. Five $w^{1118}$; WTB virgin females were presented with a choice between two unmated Tre1-GAL4/Y; UAS-TraF $/+$ males and two $w^{1118} ;$ WTB and allowed to mate for 2 days. According to our pedigree, $75 \%$ of the progeny of Tre1-GALA/Y;UAS-Tra ${ }^{F} /+$ males should have colored eyes, while none of the progeny of $w^{1118}$; WTB males will have colored eyes (Figure 8). Therefore, if mating success is equal between the two genotypes, the expected progeny eye color ratio is $37.5 \%$ colored eyed to $62.5 \%$ white eyed. Deviation from this ratio indicates altered fitness for a group.

We found that in 9 of 12 vials, Tre1-GAL4/Y; UAS-Tra ${ }^{F} /+$ males were at a competitive advantage compared with control males. Overall, 49\% (304 of 619) of offspring were non-white, an overrepresentation of $31 \%$ relative to the expectation for equal success in mating (Table 2). Thus, under laboratory conditions, the rapid courtship 
initiation seen in $\operatorname{Tre} 1-G A L 4 / Y$; $U A S-T r a^{F} /+$ males provide a competitive advantage over wild type males. 


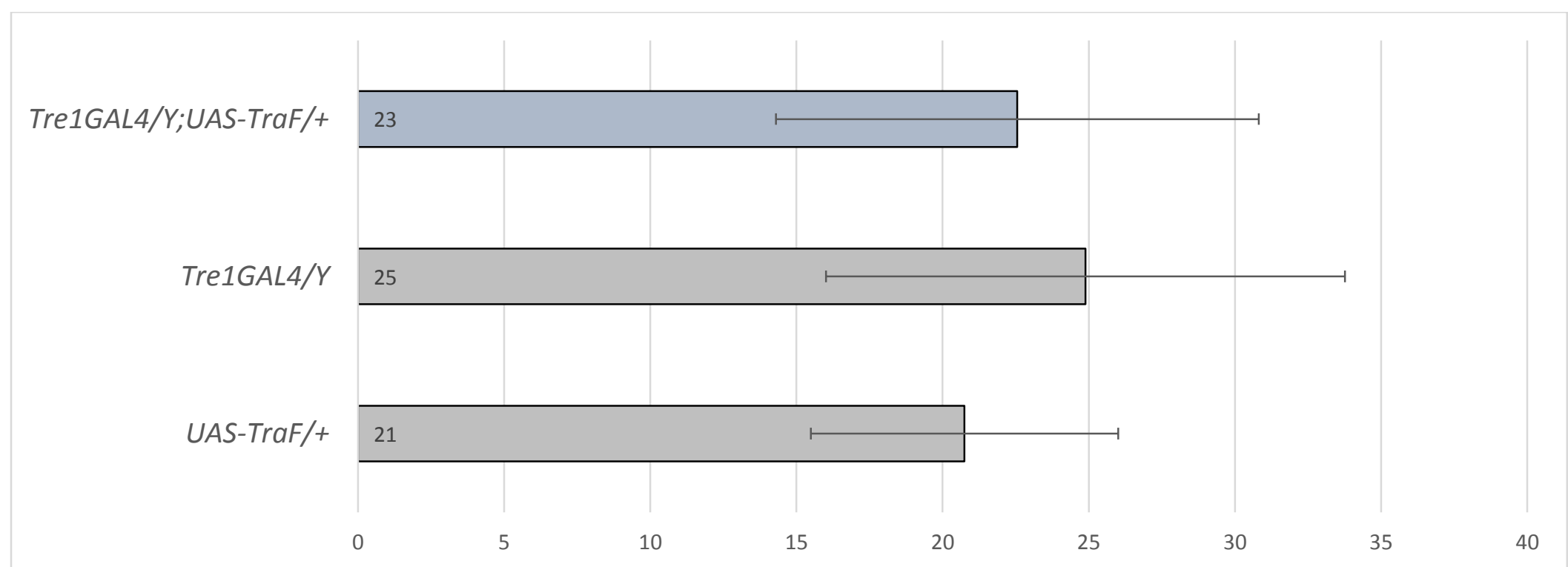

Figure 7. Noncompetitive mating assay. Tre1-GALA/Y; UAS-TraF/+ males produce nearly identical numbers of offspring compared with heterozygous controls. Tre 1-GALA/Y;UAS-Tra ${ }^{F} /+$ males produce an average of 23 offspring per male, whereas the $U A S-T r a^{F} /+$ and Tre 1-GAL4/Y heterozygous background controls produced an average of 21 and 25 offspring (shown as grey columns). One-way ANOVA, $\mathrm{n}=16$ vials per genotype. 


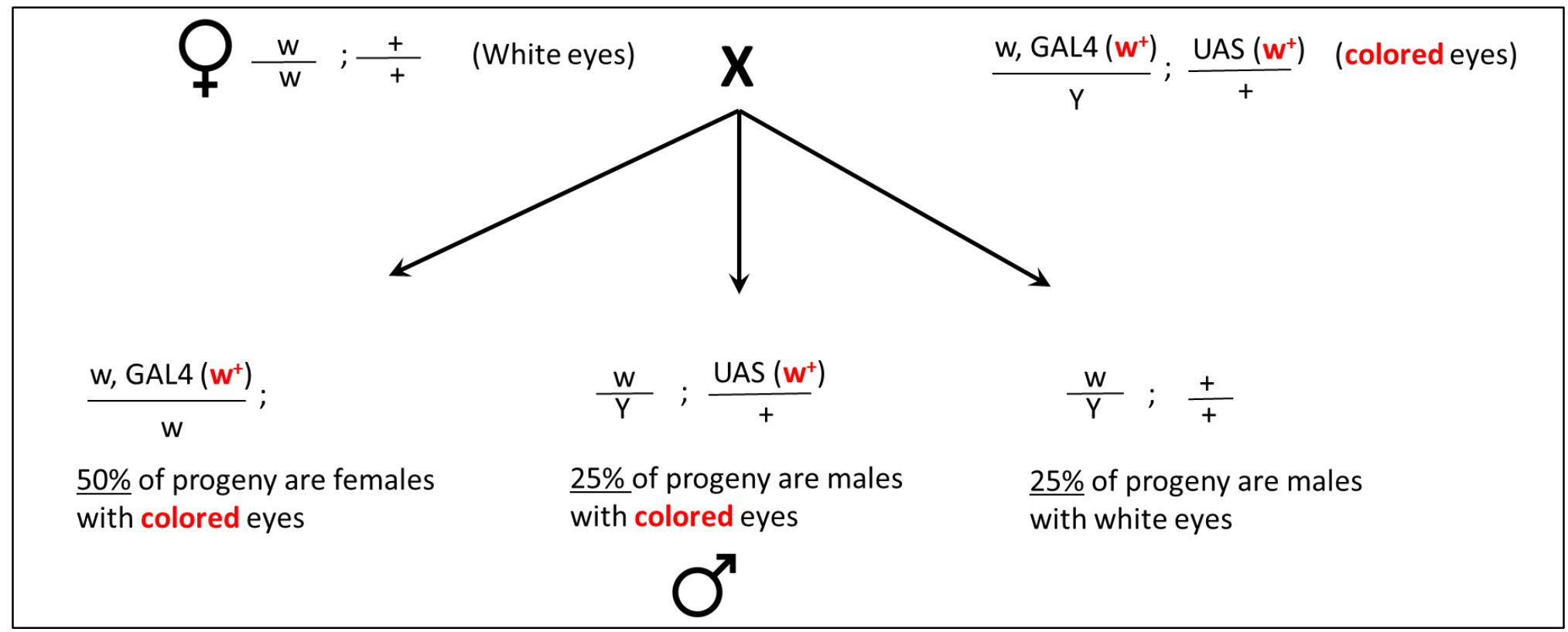

Figure 8. Expected progeny of Tre1-GALA/Y; UAS-TraF males. We expected 75\% of the offspring of Tre1-GAL4/Y; UAS-TraF males will have colored eyes. If mating success is equal with white-eyed control males, $37.5 \%$ of the resulting offspring will have colored eyes. 
Table 2. Competitive Mating Assay.

\begin{tabular}{|c|c|c|c|c|c|}
\hline Male Genotype & Competitor Male & Nonwhite Offspring (\%) & $\begin{array}{l}\text { Expected Nonwhite } \\
\text { Offspring }(\%)\end{array}$ & $\begin{array}{l}\text { Total } \\
\text { Offspring }\end{array}$ & $\chi^{2}$ (P-value) \\
\hline $\begin{array}{l}\text { Tre1-GALA/Y; } \\
\text { UAS-TraF/+ }\end{array}$ & $w^{1118} ; W T B$ & $304(49.1)$ & $232(37.5)$ & 336 & $35.6(\mathrm{P}<0.0001)$ \\
\hline Tre1-GALA/Y;+ & $w^{1118} ; W T B$ & $141(43.8)$ & $161(50)$ & 302 & $4.7(\mathrm{P}=0.030)$ \\
\hline
\end{tabular}

Notes. Tre1-GAL4/Y; UAS-Tra ${ }^{F} /+$ males have a competitive advantage compared with control males where $49 \%$ of offspring have colored eyes (expected 37.5\%). Tre $1-G A L 4 / Y$; + serves as a heterozygous control. $X^{2}$ test, $\mathrm{n}=638$. 


\section{Tre1-GAL4 Neurons Are Not Required to Distinguish Mated from Unmated}

\section{Females}

Female D. melanogaster are recalcitrant to a second mating; thus, male flies are less likely to initiate courtship with mated females. The identification of mated vs. unmated females is mediated by nonvolatile inhibitory cuticle hydrocarbons via gustatory receptors during the "tapping" step of courtship (Pavlou \& Goodwin, 2013). In addition, males must also select for mates of the correct sex as well as species. The competitive fertility assay tested a specific scenario where only unmated conspecific females (the ideal mate) were presented to the males. Thus it is possible that Tre1-GALA/Y; UAS$\operatorname{Tra}^{F} /+$ males skip a mate-identification checkpoints during courtship and thus achieve a relative reproductive advantage under laboratory conditions. To test this hypothesis, we tested the latency to court in $\operatorname{Tr} 1-G A L 4 / Y ; U A S-T r a^{F} /+$ males with mated females.

When presented with mated $w^{1118}$; WTB females, Tre1-GALA/Y; UAS-TraF $/+$ males showed a normal delay in courtship initiation relative to unmated females. Courtship initiation in these males were delayed by $17.6 \mathrm{~s}$ compared to unmated $w^{1118}$; WTB females (Table 3). Furthermore there was no difference between Tre1GALA/Y;UAS-TraF $/+$ males and control males in time to courtship initiation with mated females which all averaged $41 \mathrm{~s}$. This uniformity suggests that the Tre1-GALA expressing neurons are not required for males to discern mated from unmated females. 
Table 3. Courtship Latency of D. melanogaster Males with Mated Females

\begin{tabular}{lll}
\hline Male Genotype & Unmated Female & Mated Female \\
\hline TreI-GALA/Y;UAS-Tra ${ }^{F} /+$ & $23.5 \pm 4.4 \mathrm{~s}$ & $41.09 \pm 5.87 \mathrm{~s}(\mathrm{P}<0.05)$ \\
TreI-GALA/Y;+ & $28.9 \pm 4.6 \mathrm{~s}$ & $40.85 \pm 9.6 \mathrm{~s}(\mathrm{~ns})$ \\
$+/ U A S-T r{ }^{F}$ & $32 \pm 4.5 \mathrm{~s}$ & $41.2 \pm 4.0 \mathrm{~s} 8.0(\mathrm{~ns})$ \\
\hline
\end{tabular}

Notes. Tre 1-GAL4/Y;UAS-Tra ${ }^{F} /+$ males display the expected increase in latency to court when paired with mated females. Statistics were performed using two-way ANOVA on logtransformed courtship data to obtain equal variances. Tukey's HSD was used for pair-wise comparison. Data shown has outliers removed and without log transformation. $\pm \mathrm{SD}$, s denotes seconds, $\mathrm{n}=18-23$ males.

\section{Tre1-GAL4 Neurons Are Not Required to Distinguish Male Flies from Female Flies}

Among the most well-known effects of fru mutation in males is the indiscriminate courtship of both males and females (Hall 1994). Mutant males often court other male flies as vigorously as females, and when fru mutant males are placed in groups of males a snake-like chaining behavior occurs in which each male in the chain is simultaneously a courter and recipient. Male-male courtship is sometimes observed in wild type males, but the delay in courtship initiation compared with virgin females is significant. We therefore tested the ability of $\operatorname{Tre} 1-G A L 4 / Y ; U A S-T r a^{F} /+$ males to identify male flies as inappropriate courtship targets. We found courtship latency was drastically increased when male flies were presented with unmated males (Table 4). In fact, Tre 1GALA/Y;UAS-Tra ${ }^{F} /+$ males showed a greater delay in courting unmated males, though this effect was not statistically significant. These results indicated that the Tre1-GAL4 cells are not required to differentiate the sex of potential mates. 
Table 4. Courtship Latency of D. melanogaster Males with Unmated Males

\begin{tabular}{lll}
\hline Male Genotype & Unmated Female & Unmated Male \\
\hline Tre1-GALA/Y;UAS-Tra ${ }^{F} /+$ & $23.5 \pm 4.4 \mathrm{~s}$ & $386 \pm 128 \mathrm{~s}(\mathrm{P}<0.05)$ \\
Tre1-GALA/Y;+ & $28.9 \pm 4.6 \mathrm{~s}$ & $205 \pm 65 \mathrm{~s}(\mathrm{P}<0.05)$ \\
+UAS-TraF & $32.0 \pm 4.5 \mathrm{~s}$ & $494 \pm 291 \mathrm{~s}(\mathrm{P}<0.05)$ \\
Wild type & $63.9 \pm 8.6 \mathrm{~s}$ & $415 \pm 97.6 \mathrm{~s}(\mathrm{P}<0.05)$ \\
\hline
\end{tabular}

Notes. Tre1-GALA/Y;UAS-Tra ${ }^{F} /+$ display a normal increase in courtship latency when presented with unmated males. Statistics were performed using two-way ANOVA on log-transformed courtship timing data. Tukey's HSD was used for pair-wise comparison (unmated female vs. unmated male). Data shown has outliers removed and without log transformation. $\pm \mathrm{SD}, \mathrm{s}$ denotes seconds, $\mathrm{n}=3-24$ males.

\section{Tre 1-GAL4 Neurons Are Not Required for Identification of Conspecific Females}

In their natural environment, D. melanogaster encounter sibling species, with whom, if successful copulation occurred, the offspring would be sterile. Therefore, it is imperative for male flies to select conspecific partners. We therefore tested whether the Tre1-GAL4 cells are required to distinguish conspecific females from females of two closely-related species, D. simulans and D. mauritiana. Tre1-GAL4/Y;UAS-TraF/+ males, when presented with unmated $D$. simulans females, displayed a significantly delayed wing song initiation (57.7 seconds compared with 13.9 seconds with $D$. melanogaster females) (Table 5). The heterozygous controls, Tre1-GALA/Y;+ and +/UAS-TraF, each had nonsignificant increases in courtship latency with D. simulans females.

Similarly, when Tre1-GAL4/Y;UAS-TraF/+ males were presented with unmated D. mauritiana females, all genotypes showed a significant increase in wing song initiation with an increase mean latency higher than $D$. simulans. The delay was likely 
more profound due to the fact that $D$. melanogaster and $D$. simulans are more closely related than either with D. mauritiana (Cobb et al., 1988).

Table 5. Courtship Latency of D. melanogaster Males with Females of Sibling Species.

\begin{tabular}{llll}
\hline Male Genotype & D. melanogaster & D. simulans & D. mauritiana \\
\hline & & & \\
Tre1-GAL4/Y;UAS-TraF/+ & $13.9 \pm 6.2 \mathrm{~s}$ & $57.7 \pm 12.5 \mathrm{~s} *$ & $87.2 \pm 23.2 \mathrm{~s} *$ \\
Tre1-GAL4/Y;+ & $36.5 \pm 5.0 \mathrm{~s}$ & $50.2 \pm 7.8 \mathrm{~s}(\mathrm{~ns})$ & $76.4 \pm 16.7 \mathrm{~s} *$ \\
$+/ U A S-T r a F$ & $29.8 \pm 2.7 \mathrm{~s}$ & $38.7 \pm 6.3 \mathrm{~s}(\mathrm{~ns})$ & $87.2 \pm 23.3 \mathrm{~s} *$ \\
\hline
\end{tabular}

Notes. Tre1-GAL4/Y;UAS-TraF/+ display the expected increase of courtship latency when presented with $D$. simulans and $D$. mauritiana. Statistics were performed on using two wayANOVA on log-transformed courtship timing to obtain equal variances, Mean latency shown on the graph was back-transform. Tukey's HSD was used for paired-wise comparison. $\pm \mathrm{SD}, \mathrm{s}$ denotes seconds, * denotes $\mathrm{P}<0.05, \mathrm{n}=18-24$ males.

\section{Tre 1-GAL4 May Be a Partial Loss of Function Allele of Tre1}

The Tre1-GAL4 transposon is inserted into the coding region of the $\mathrm{G}$ proteincoupled receptor (GPCR) gene Trapped in endoderm-1 (Tre1). The Tre1-GAL4

transgene is greater than $11 \mathrm{~kb}$ in length, and is located on the sixth exon of all three Tre 1 transcripts; its size and location suggest that it disrupts the cytoplasmic domain between the sixth and seventh transmembrane domains of the protein (Figure 9). Therefore, we hypothesized that Tre1-GAL4 is very likely a loss-of-function allele of Tre1. To test this hypothesis, we used quantitative reverse-transcriptase mediated PCR (qRT-PCR) to examine Tre1 transcript levels in Tre1-GAL4 animals. Because Tre1 is known to regulate germ cell migration, we examined the transcriptional levels during the embryonic stage (Kunwar et al., 2008). As predicted, Tre1-GAL4 disrupted embryonic expression of Tre1, but the gene's expression level during the pupal stage remained unchanged (Figure $10)$. 


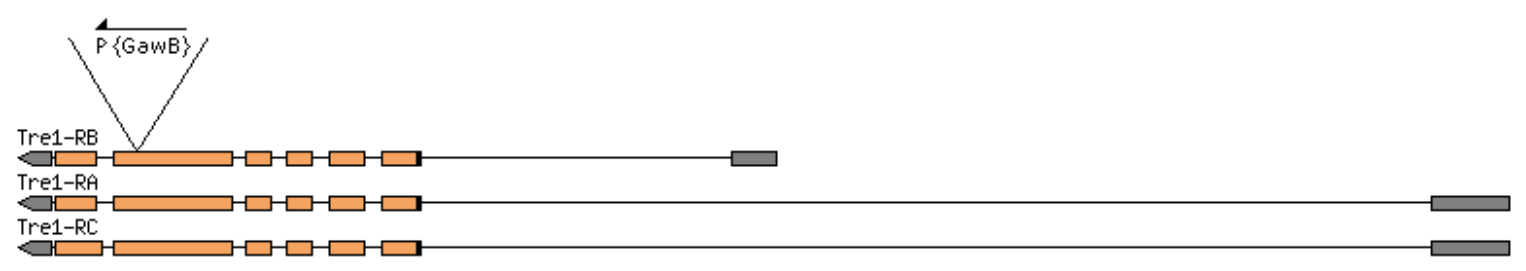

Figure 9. Schematic diagram of the Tre1 gene. Tre1-RA, Tre1-RB, and Tre1-RC encode the same protein, but Tre1-RA is initiated $\sim 3 \mathrm{~kb}$ further upstream. The Tre1-GALA transposon is inserted into the sixth exon of all three transcripts.

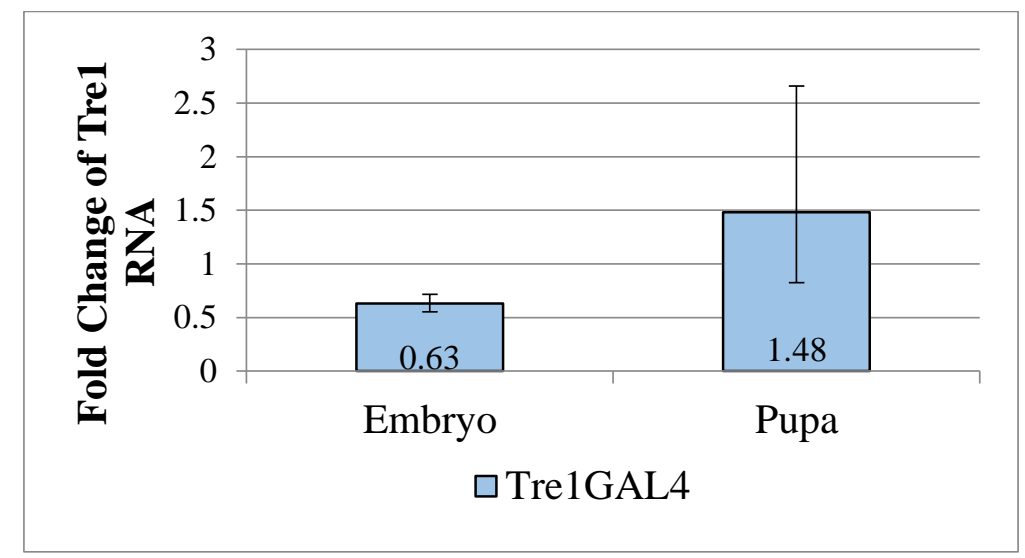

Figure 10. Expression of Tre1 RNA in Tre1-GAL4 flies. Embryonic expression in Tre1 was decreased by $37 \%$, while expression in pupae was not significantly changed relative to control animals. Expression in Tre1-GAL4 flies shown are relative to the $w^{1118}$; WTB control strain (represented by a transcript level of 1). Error bars denote high and low ranges of a single standard deviation, $\mathrm{n}=3$. 


\section{Discussion}

In summary, feminization of Tre 1-GALA expressing cells resulted in rapid courtship initiation and increased mating success. The Tre1-GAL4 neurons were not required for mate identification and were expressed in a sexually dimorphic pattern in both the CNS and PNS. Finally, Tre1-GALA was a weak loss-of-function allele of Tre1, which may exert some of the phenotypes seen.

Courtship in D. melanogaster involves a complex but stereotyped array of sexually dimorphic behaviors mediated by sensory inputs via the peripheral nervous system and integrated in the central nervous system (Hall 1994; Baker et al., 2001; Demir and Dickson 2005; Dickson 2008; Pavlou and Goodwin 2013). The resulting behavioral phenotypes are dependent upon expression of the male-specific isoforms of the transcription factor Fru ${ }^{\mathrm{M}}$ (Demir and Dickson 2005). Here we identified a unique role for $\mathrm{Fru}^{\mathrm{M}}$ proteins. When cells expressing Tre 1-GAL4 were feminized via expression of the female splice form of $\operatorname{Tra}\left(\operatorname{Tra}^{\mathrm{F}}\right)$, which led to female-specific splicing of $f r u$ and therefore loss of $f r u^{M}$ transcripts, male flies initiated courtship much more quickly than wild type flies. Thus, in the Tre I-GALA cells, Fru ${ }^{\mathrm{M}}$ proteins were uniquely required to reduce the speed of courtship initiation. In addition, we found that Tre 1 expression under GAL4 control was expressed in a sexually dimorphic pattern in the adult OSNs and central nervous system and that the Tre1-GALA neurons were not required for distinguishing conspecific females, unmated females, or males from females. 


\section{D. melanogaster Mating Behavior and the Role of the Tre1-GAL4 Neurons}

The identified GAL4 transgene (Tre1-GAL4) is inserted into the coding sequence of the Trapped in endoderm-1 gene. When this GAL4 line was used to drive expression of either an RNAi targeting $f r u^{M}$ or the feminizing transgene $U A S-T r a^{F}$, it resulted in male flies that initiated courtship and achieved copulation much more quickly than control animals. Typically, loss of $f r u^{M}$ results in slowed, abnormal, or absent courtship (Demir and Dickson 2005), but the feminization of Tre1 expressing-neurons does the opposite, resulting in a mating advantage for Tre1-GAL4/Y;UAS-Tra ${ }^{F}$ males. Given these observations, it seems counterintuitive that neurons exist specifically for slowing down courtship. To address this conundrum, we tested several hypotheses about the function of the Tre1-GAL4 neurons.

First, the cells may participate in "quality control," ensuring the correct performance of the courtship ritual. This hypothesis predicts that courtship quality is reduced in animals displaying rapid courtship initiation, leading to reduced mating and reproductive success in competition with wild type males. On the contrary, Tre 1-GAL4 IY; UAS-Tra ${ }^{F}$ males appeared to perform all steps of the ritual correctly, leading to the reproductive advantage seen in the fertility assays.

Second, the Tre1-GALA cells may function in correct mate identification, allowing males to distinguish an appropriate mate from a less appropriate mate. This theory predicts that rapid courtship reflects the skipping of the species-specific wing song, or failure to recognize visual cues. However, we tested three well-characterized aspects of mate selection in regard to recipient type: mated vs. unmated female, female vs. male, 
and sibling species. In all three aspects, $\operatorname{Tre} 1-G A L 4 / Y$; $U A S-T r a^{F} /+$ males were normal. Our experiments indicated that the Tre1-GAL4 cells were not involved in the ability of $D$. melanogaster males to identify conspecific females, nor did they appear to be required to distinguish virgin from non-virgin females or males from females.

\section{The Tre1 Receptor and Courtship Behavior}

Tre 1-GAL4 is a transposon inserted into the coding sequence of the G proteincoupled receptor (GPCR) gene Trapped in endoderm-1 (Tre1). The Tre1 GPCR has two known functions in D. melanogaster. First, it is necessary for transepithelial migration of maternal germ cells through the posterior midgut epithelium (Kunwar et al., 2008;

Kunwar et al., 2003). Second, it is needed for the determination of neuroblast polarity during asymmetric stem cell division in the developing central nervous system (Fuse et al., 2003; Yoshiura et al., 2012). The ligand for Tre1 is not known, but based on sequence similarity, it belongs to a family of proteins related to the GPCR CXCR4 (Kunwar et al., 2003). Trel is closely related to the vertebrate histamine and melatonin receptors and more distantly related to chemokine receptors (Kunwar et al., 2003).

Asymmetric cell division in neuroblasts requires modulation of the cytoskeleton (Fuse et al., 2003; Yoshiura et al., 2012), whereas germ cell migration requires polarized distribution of E-cadherin (Kunwar et al., 2008) (as well as reorganization of the cytoskeleton). In migrating germ cells, the role of Tre1 appears to be to change the polarity of the cells such that they are oriented toward their ultimate target, and to facilitate the loss of cell-cell adhesion between germ cells, thereby priming the cells to be receptive to further guidance signals (Kunwar et al. 2008). Based on these data, Tre1 is 
likely a neuropeptide or protein hormone receptor that, upon activation, leads to a polarization of the cell for asymmetric cell division or migration. This proposed function for Trel is consistent with a role in axon outgrowth or synapse formation.

The Tre1-GAL4 transgene is a large insertion (more than $11 \mathrm{~kb}$ ) in the proteincoding sequence of Trel, but how this affects the protein sequence is not known. It is possible that cryptic splice sites within the P-element result in the translation of a hybrid, nonfunctional protein, and this may contribute synergistically to the behavioral phenotype seen in $\operatorname{Tr} 1-G A L 4 / Y ; U A S-T r a^{F} /+$ males. This leaves open the possibility that some of the complexity of phenotype we are seeing is due to varying levels of Trel function due the transgene insertion (Figure 9 and 10). Because we found that Tre1GAL4 is expressed in a sexually dimorphic pattern in the adult nervous system, one possible mechanism for Trel in courtship behavior is that Trel may mediate the development and targeting of sex-specific neurons. In support of this hypothesis, we have data indicating that loss-of-function mutations in Tre1 display rapid courtship initiation as well as other courtship defects (Luu et al., 2016)

Currently, we are in the process of characterizing a mutant strain, Tre $1^{E P 496}$, in courtship and fertility assays. We will also test downstream components of the known Tre1 signaling pathway for courtship and mating phenotypes.

\section{Future Directions}

Feminization of the Tre1-GAL4 neurons causes rapid courtship initiation, and this phenotype led to increased reproductive success in competition with normal males. This advantage indicates that $\operatorname{Tr} 1-G A L 4 / Y$; UAS-Tra ${ }^{F}$ males perform the courtship ritual 
correctly and completely. Tre1-GAL4 is expressed in a sexually dimorphic pattern, suggesting the existence of neural circuitry that is specific to male flies that regulates the speed of courtship initiation.

To further understand the mechanism of how Tre 1-GALA/Y; UAS-Tra ${ }^{F}$ affects neural activities, we will determine whether the Tre1-GALA/Y; UAS-Tra ${ }^{F}$ courtship phenotype is due to loss or gain of neuronal activity. We will undertake a series of experiments to drive expression of a temperature-sensitive allele of $\operatorname{shibiri}\left(\operatorname{sh}^{\mathrm{ts}}\right)$, the gene encoding the fly homolog of dynamin (Gonzalez-Bellido, et al, 2009), as well as the heat-sensitive TrpA1 (Rosenzweig et al., 2005) channel in the Tre 1-GAL4 neurons. If rapid courtship results from inactivation of the Tre1-GAL4 cells, expression of $s h i^{t s}$ should recapitulate the phenotype. On the other hand, if rapid courtship results from inappropriate neuronal activity, activation of TrpA1 in the Tre1-GALA cells should phenocopy Tre1-GALA/Y; UAS-Tra ${ }^{F}$.

It is possible, even likely, that the GALA expression does not accurately reflect the full Tre 1 expression pattern. Further characterization of the expression of Tre1 would require the generation of an antibody against the Tre1 receptor followed by immunofluorescence imaging. 


\section{Conclusions}

In this thesis we identified rapid courtship initiation time as a unique role for the loss of $f r u^{M}$ expression. Male D. melanogaster with decreased $\mathrm{Fru}^{\mathrm{M}}$ in Tre 1 -expressing neurons initiate courtship much faster than wild type males, resulting in a reproductive advantage. We localized this effect to the olfactory sensory neurons in the antennae which likely synapse with neurons in the lateral horn, an area known for integrating innate chemical signals. Future studies will explore the function of the Tre 1 signal transduction pathway in mating behavior as well as confirm the Trel expression pattern. 


\section{References}

Alivisatos, A. P., Chun, M., Church, G. M., Greenspan, R. J., Roukes, M. L., \& Yuste, R. (2012). The brain activity map project and the challenge of functional connectomics. Neuron, 74, 970-974. http://doi.org/10.1016/j.neuron.2012.06.006

Anand, A., Villella, A., Ryner, L. C., Carlo, T., Goodwin, S. F., Song, H. J., Taylor, B. J. (2001). Molecular genetic dissection of the sex-specific and vital functions of the Drosophila melanogaster sex determination gene fruitless. Genetics, 158, 1569-1595.

Antony, C., \& Jallon, J.-M. (1982). The chemical basis for sex recognition in Drosophila melanogaster. Journal of Insect Physiology, 28, 873-880. http://doi.org/10.1016/0022-1910(82)90101-9

BDGP: Inverse PCR \& Cycle Sequencing of P-element insertions for STS generation. (n.d.). Retrieved March 29, 2016, from http://www.fruitfly.org/about/methods/inverse.pcr.html

Boake, C. R. B., DeAngelis, M. P., \& Andreadis, D. K. (1997). Is sexual selection and species recognition a continuum? Mating behavior of the stalk-eyed fly Drosophila heteroneura. Proceedings of the National Academy of Sciences of the United States of America, 94, 12442-12445.

Cobb, M., Burnet, B., \& Connolly, K. (1988). Sexual isolation and courtship behavior in Drosophila simulans, D. mauritiana, and their interspecific hybrids. Behavior Genetics, 18, 211-225. http://doi.org/10.1007/BF01067843

Cobb, M., \& Jallon, J.-M. (1990). Pheromones, mate recognition and courtship stimulation in the Drosophila melanogaster species sub-group. Animal Behaviour, 39, 1058-1067. http://doi.org/10.1016/S0003-3472(05)80778-X

Datta, S. R., Vasconcelos, M. L., Ruta, V., Luo, S., Wong, A., Demir, E., Axel, R. (2008). The Drosophila pheromone cVA activates a sexually dimorphic neural circuit. Nature, 452, 473-477. http://doi.org/10.1038/nature06808

Demir, E., \& Dickson, B. J. (2005). fruitless splicing specifies male courtship behavior in Drosophila. Cell, 121, 785-794. http://doi.org/10.1016/j.cell.2005.04.027 
Ewing, A. W., \& Bennet-Clark, H. C. (1968). The courtship songs of Drosophila. Behaviour, 31(3/4), 288-301.

Ferveur, J. F., \& Sureau, G. (1996). Simultaneous influence on male courtship of stimulatory and inhibitory pheromones produced by live sex-mosaic Drosophila melanogaster. Proceedings. Biological Sciences / The Royal Society, 263, 967973. http://doi.org/10.1098/rspb.1996.0143

Fuse, N., Hisata, K., Katzen, A. L., \& Matsuzaki, F. (2003). Heterotrimeric G proteins regulate daughter cell size asymmetry in Drosophila neuroblast divisions. Current Biology: CB, 13, 947-954.

Gonzalez-Bellido, P. T., Wardill, T. J., Kostyleva, R., Meinertzhagen, I. A., \& Juusola, M. (2009). Overexpressing temperature-sensitive dynamin decelerates phototransduction and bundles microtubules in Drosophila photoreceptors. The Journal of Neuroscience, 29, 14199-14210. http://doi.org/10.1523/JNEUROSCI.2873-09.2009

Greenspan, R. J., \& Ferveur, J. F. (2000). Courtship in Drosophila. Annual Review of Genetics, 34, 205-232. http://doi.org/10.1146/annurev.genet.34.1.205

Grillet, M., Dartevelle, L., \& Ferveur, J.-F. (2006). A Drosophila male pheromone affects female sexual receptivity. Proceedings of the Royal Society of London B: Biological Sciences, 273, 315-323. http://doi.org/10.1098/rspb.2005.3332

Gupta, N., \& Stopfer, M. (2012). Functional analysis of a higher olfactory center, the lateral horn. The Journal of Neuroscience, 32, 8138-8148. http://doi.org/10.1523/JNEUROSCI.1066-12.2012

Hall, J. C. (1994). The mating of a fly. Science, 264, 1702-1714.

Heinrichs, V., Ryner, L. C., \& Baker, B. S. (1998). Regulation of sex-specific selection of fruitless 5' splice sites by transformer and transformer-2. Molecular and Cellular Biology, 18, 450-458.

Jefferis, G. S. X. E., Potter, C. J., Chan, A. M., Marin, E. C., Rohlfing, T., Maurer, C. R., \& Luo, L. (2007). Comprehensive maps of Drosophila higher olfactory centers: spatially segregated fruit and pheromone representation. Cell, 128, 1187-1203. http://doi.org/10.1016/j.cell.2007.01.040 
Keene, A. C., \& Waddell, S. (2007). Drosophila olfactory memory: single genes to complex neural circuits. Nature Reviews Neuroscience, 8, 341-354. http://doi.org/10.1038/nrn2098

Kimura, K.-I., Ote, M., Tazawa, T., \& Yamamoto, D. (2005). Fruitless specifies sexually dimorphic neural circuitry in the Drosophila brain. Nature, 438, 229233. http://doi.org/10.1038/nature04229

Krupp, J. J., Kent, C., Billeter, J.-C., Azanchi, R., So, A. K.-C., Schonfeld, J. A., ... Levine, J. D. (2008). Social experience modifies pheromone expression and mating behavior in male Drosophila melanogaster. Current Biology, 18, 13731383. http://doi.org/10.1016/j.cub.2008.07.089

Kunwar, P. S., Sano, H., Renault, A. D., Barbosa, V., Fuse, N., \& Lehmann, R. (2008). Tre1 GPCR initiates germ cell transepithelial migration by regulating Drosophila melanogaster E-cadherin. The Journal of Cell Biology, 183, 157-168. http://doi.org/10.1083/jcb.200807049

Kurtovic, A., Widmer, A., \& Dickson, B. J. (2007). A single class of olfactory neurons mediates behavioural responses to a Drosophila sex pheromone. Nature, 446, 542-546. http://doi.org/10.1038/nature05672

Lai, J. S.-Y., Lo, S.-J., Dickson, B. J., \& Chiang, A.-S. (2012). Auditory circuit in the Drosophila brain. Proceedings of the National Academy of Sciences, 109, 26072612. http://doi.org/10.1073/pnas.1117307109

Lee, G., Foss, M., Goodwin, S. F., Carlo, T., Taylor, B. J., \& Hall, J. C. (2000). Spatial, temporal, and sexually dimorphic expression patterns of the fruitless gene in the Drosophila central nervous system. Journal of Neurobiology, 43, 404-426.

Liu, W., Liang, X., Gong, J., Yang, Z., Zhang, Y.-H., Zhang, J.-X., \& Rao, Y. (2011). Social regulation of aggression by pheromonal activation of Or65a olfactory neurons in Drosophila. Nature Neuroscience, 14, 896-902. http://doi.org/10.1038/nn.2836

Luu, P., Zaki, S. A., Tran, D. H., \& French, R. L. (2016). A novel gene controlling the timing of courtship initiation in Drosophila melanogaster. Genetics, 202(3), 1043-1053. http://doi.org/10.1534/genetics.115.183061

Makki, R., Cinnamon, E., \& Gould, A. P. (2014). The development and functions of oenocytes. Annual Review of Entomology, 59, 405-425. http://doi.org/10.1146/annurev-ento-011613-162056 
Manoli, D. S., Foss, M., Villella, A., Taylor, B. J., Hall, J. C., \& Baker, B. S. (2005). Male-specific fruitless specifies the neural substrates of Drosophila courtship behaviour. Nature, 436, 395-400. http://doi.org/10.1038/nature03859

Marin, E. C., Jefferis, G. S. X. E., Komiyama, T., Zhu, H., \& Luo, L. (2002). Representation of the glomerular olfactory map in the Drosophila brain. Cell, 109, 243-255. http://doi.org/10.1016/S0092-8674(02)00700-6

Markow, T. A. (1987). Behavioral and sensory basis of courtship success in Drosophila melanogaster. Proceedings of the National Academy of Sciences of the United States of America, 84, 6200-6204.

Markow, T. A., Quaid, M., \& Kerr, S. (1978). Male mating experience and competitive courtship success in Drosophila melanogaster. Nature, 276, 821-822. http://doi.org/10.1038/276821a0

Mcrobert, S. P., \& Tompkins, L. (1987). The effect of light on the sexual behavior of Drosophila affinis. Behavioral and Neural Biology, 47, 151-157. http://doi.org/10.1016/S0163-1047(87)90257-3

Meissner, G. W., Manoli, D. S., Chavez, J. F., Knapp, J.-M., Lin, T. L., Stevens, R. J., Baker, B. S. (2011). Functional dissection of the neural substrates for sexual behaviors in Drosophila melanogaster. Genetics, 189, 195-211. http://doi.org/10.1534/genetics.111.129940

Neville, M. C., Nojima, T., Ashley, E., Parker, D. J., Walker, J., Southall, T., ... Goodwin, S. F. (2014). Male-specific fruitless isoforms target neurodevelopmental genes to specify a sexually dimorphic nervous system. Current Biology, 24, 229-241. http://doi.org/10.1016/j.cub.2013.11.035

Pavlou, H. J., \& Goodwin, S. F. (2013). Courtship behavior in Drosophila melanogaster: towards a "courtship connectome." Current Opinion in Neurobiology, 23, 76-83. http://doi.org/10.1016/j.conb.2012.09.002

Rein, K., Zöckler, M., Mader, M. T., Grübel, C., \& Heisenberg, M. (2002). The Drosophila standard brain. Current Biology, 12, 227-231. http://doi.org/10.1016/S0960-9822(02)00656-5

Rosenzweig, M., Brennan, K. M., Tayler, T. D., Phelps, P. O., Patapoutian, A., \& Garrity, P. A. (2005). The Drosophila ortholog of vertebrate TRPA1 regulates thermotaxis. Genes \& Development, 19, 419-424. http://doi.org/10.1101/gad.1278205 
Ruta, V., Datta, S. R., Vasconcelos, M. L., Freeland, J., Looger, L. L., \& Axel, R. (2010). A dimorphic pheromone circuit in Drosophila from sensory input to descending output. Nature, 468, 686-690. http://doi.org/10.1038/nature09554

Ryner, L. C., Goodwin, S. F., Castrillon, D. H., Anand, A., Villella, A., Baker, B. S., ... Wasserman, S. A. (1996). Control of male sexual behavior and sexual orientation in Drosophila by the fruitless Gene. Cell, 87, 1079-1089. http://doi.org/10.1016/S0092-8674(00)81802-4

Sakai, T., Isono, K., Tomaru, M., \& Oguma, Y. (1997). Light-affected male following behavior is involved in light-dependent mating in Drosophila melanogaster. Genes \& Genetic Systems, 72, 275-281. http://doi.org/10.1266/ggs.72.275

Savarit, F., Sureau, G., Cobb, M., \& Ferveur, J.-F. (1999). Genetic elimination of known pheromones reveals the fundamental chemical bases of mating and isolation in Drosophila. Proceedings of the National Academy of Sciences, 96, 9015-9020. http://doi.org/10.1073/pnas.96.16.9015

Schmittgen, T. D., \& Livak, K. J. (2008). Analyzing real-time PCR data by the comparative C(T) method. Nature Protocols, 3, 1101-1108.

Shirangi, T. R., Stern, D. L., \& Truman, J. W. (2013). Motor control of Drosophila courtship song. Cell Reports, 5, 678-686.

http://doi.org/10.1016/j.celrep.2013.09.039

Shorey, H. H. (1962). Nature of the sound produced by Drosophila melanogaster during courtship. Science (New York, N.Y.), 137, 677-678. http://doi.org/10.1126/science.137.3531.677

Tram, U., \& Wolfner, M. F. (1998). Seminal fluid regulation of female sexual attractiveness in Drosophila melanogaster. Proceedings of the National Academy of Sciences of the United States of America, 95, 4051-4054.

Tran, D. H., Meissner, G. W., French, R. L., \& Baker, B. S. (2014). A small subset of fruitless subesophageal neurons modulate early courtship in Drosophila. PLoS ONE, 9, e95472. http://doi.org/10.1371/journal.pone.0095472

von Philipsborn, A. C., Jörchel, S., Tirian, L., Demir, E., Morita, T., Stern, D. L., \& Dickson, B. J. (2014). Cellular and behavioral functions of fruitless Isoforms in Drosophila courtship. Current Biology, 24, 242-251. http://doi.org/10.1016/j.cub.2013.12.015 
Wang, L., Han, X., Mehren, J., Hiroi, M., Billeter, J.-C., Miyamoto, T., ... Anderson, D. J. (2011). Hierarchical chemosensory regulation of male-male social interactions in Drosophila. Nature Neuroscience, 14, 757-762.

http://doi.org/10.1038/nn.2800

Wu, J. S., \& Luo, L. (2006). A protocol for dissecting Drosophila melanogaster brains for live imaging or immunostaining. Nature Protocols, 1, 2110-2115. http://doi.org/10.1038/nprot.2006.336

Yu, J. Y., Kanai, M. I., Demir, E., Jefferis, G. S. X. E., \& Dickson, B. J. (2010). Cellular organization of the neural circuit that drives Drosophila courtship behavior. Current Biology, 20, 1602-1614.

http://doi.org/10.1016/j.cub.2010.08.025 